\title{
The prospect of synthesis of PES/PEG blend membranes using blend NMP/DMF for CO2/N2 separation
}

\author{
Fadel Abdul Hadi Juber ${ }^{1} \cdot$ Zeinab Abbas Jawad $^{2}\left(\mathbb{D} \cdot\right.$ Bridgid Lai Fui Chin $^{1} \cdot$ Swee Pin Yeap ${ }^{3} \cdot$ Thiam Leng Chew $^{4,5}$
}

Received: 16 November 2020 / Accepted: 17 March 2021 / Published online: 17 April 2021

(c) The Author(s) 2021

\begin{abstract}
Carbon dioxide $\left(\mathrm{CO}_{2}\right)$ emissions have been the root cause for anthropogenic climate change. Decarbonisation strategies, particularly carbon capture and storage (CCS) are crucial for mitigating the risk of global warming. Among all current $\mathrm{CO}_{2}$ separation technologies, membrane separation has the biggest potential for CCS as it is inexpensive, highly efficient, and simple to operate. Polymeric membranes are the preferred choice for the gas separation industry due to simpler methods of fabrication and lower costs compared to inorganic or mixed matrix membranes (MMMs). However, plasticisation and upperbound trade-off between selectivity and permeability has limited the gas separation performance of polymeric membranes. Recently, researchers have found that the blending of glassy and rubbery polymers can effectively minimise trade-off between selectivity and permeability. Glassy poly(ethersulfone) (PES) and rubbery poly(ethylene) glycol (PEG) are polymers that are known to have a high affinity towards $\mathrm{CO}_{2}$. In this paper, PEG and PES are reviewed as potential polymer blend that can yield a final membrane with high $\mathrm{CO}_{2}$ permeance and $\mathrm{CO}_{2} /$ nitrogen $\left(\mathrm{N}_{2}\right)$ selectivity. Gas separation properties can be enhanced by using different solvents in the phase-inversion process. N-Methyl-2-Pyrrolidone (NMP) and Dimethylformamide (DMF) are common industrial solvents used for membrane fabrication. Both NMP and DMF are reviewed as prospective solvent blend that can improve the morphology and separation properties of PES/PEG blend membranes due to their effects on the membrane structure which increases permeation as well as selectivity. Thus, a PES/PEG blend polymeric membrane fabricated using NMP and DMF solvents is believed to be a major prospect for $\mathrm{CO}_{2} / \mathrm{N}_{2}$ gas separation.
\end{abstract}

Keywords Gas separation · Blend membrane · Polyethersulfone · Poly(ethylene) glycol · N-Methyl-2-Pyrrolidone · Dimethylformamide

Zeinab Abbas Jawad

zjawad@qu.edu.qa

1 Department of Chemical Engineering, Faculty of Engineering and Science, Curtin University Malaysia, CDT 250, 98009 Miri, Sarawak, Malaysia

2 Department of Chemical Engineering, College of Engineering, Qatar University, P.O.Box: 2713, Doha, Qatar

3 Department of Chemical \& Petroleum Engineering, UCSI University, 56000 Cheras, Kuala Lumpur, Malaysia

4 Department of Chemical Engineering, Faculty of Engineering, Universiti Teknologi PETRONAS, Seri Iskandar 32610, Perak, Malaysia

5 CO2 Research Centre (CO2RES), Institute of Contaminant Management, Universiti Teknologi PETRONAS, Seri Iskandar 32610, Perak, Malaysia

$\begin{array}{ll}\text { Nomenclature } \\ \text { ASU } & \text { Air Separation Unit } \\ \text { CA } & \text { Cellulose Acetate } \\ \text { CCS } & \text { Carbon Capture and Storage } \\ \text { CNT } & \text { Carbon Nanotube } \\ \text { CO } & \text { Carbon Monoxide } \\ \text { CO2 } & \text { Carbon Dioxide } \\ \text { CH4 } & \text { Methane } \\ \text { DCM } & \text { Dichloromethane } \\ \text { DMF } & \text { Dimethylformamide } \\ \text { ETPU } & \text { Polyeterurethane } \\ \text { GBL } & \gamma \text {-Butyrolactone } \\ \text { GHG } & \text { Greenhouse Gas } \\ \text { GPU } & \text { Gas Permeance Unit } \\ \text { H2 } & \text { Hydrogen } \\ \text { H2O } & \text { Water } \\ \text { IGCC } & \text { Integrated Gasification Combined Cycle } \\ \text { MEA } & \text { Mono-ethanolamine } \\ \text { MMM } & \text { Mixed Matrix Membrane }\end{array}$




\begin{tabular}{|c|c|c|}
\hline $\mathrm{N} 2$ & Nitrogen & Climate change \\
\hline NIPS & Non-solvent Induced Phase Separation & \\
\hline NMP & N-Methyl-2-Pyrrolidone & Climate change has been a growing concern in the past dec- \\
\hline NOx & Nitrogen Oxide & ade. Over the last few decades, the global temperature rose \\
\hline $\mathrm{O} 2$ & Oxygen & by $0.7{ }^{\circ} \mathrm{C}$ when compared to the $1961-1990$ baseline [1]. \\
\hline PAI & Poly(amide-imide) & In comparison to temperature data from 1850 , it has been \\
\hline $\mathrm{PC}$ & Polycarbonate & observed that temperatures then were $0.4{ }^{\circ} \mathrm{C}$ lower than the \\
\hline PDMS & Polydimethylsiloxane & baseline, where the total increase in temperature was 1.1 \\
\hline Pebax ${ }^{\circledR}$ & Polyamide-bethylene Oxide & ${ }^{\circ} \mathrm{C}$ [2]. Greenhouse gas (GHG) emissions, predominantly \\
\hline PEG & Poly(ethylene) Glycol & $\mathrm{CO}_{2}$, are the major cause of this rapid temperature rise. The \\
\hline PEI & Polyetherimide & rapid increase of $\mathrm{CO}_{2}$ content in the atmosphere directly \\
\hline PES & Polyethersulfone & correlates to the global temperature increase [1]. During \\
\hline PI & Polyimide & the pre-industrial revolution era, $\mathrm{CO}_{2}$ concentration in the \\
\hline PPE & Poly(2,6-dimethyl-1,4-phenylene oxide) & atmosphere fluctuated naturally due to Milankovich cycles \\
\hline PPG & Poly(propylene) Glycol & without exceeding $300 \mathrm{ppm}$ [3]. However, the combustion \\
\hline PSA & Pressure Swing Adsorption & of non-renewable fuels such as natural gas and coal since \\
\hline PSF & Polysulfone & the industrial revolution has caused the atmospheric $\mathrm{CO}_{2}$ \\
\hline PVAc & Polyvinyl Acetate & concentration to rise well beyond $400 \mathrm{ppm}[1,4]$. Based on \\
\hline PVAm & Polyvinylamine & the United States Environmental Protection Agency [5], the \\
\hline RWE & Rheinisch-Westfälisches Elektrizitätswerk & most significant GHG pollution source is from energy and \\
\hline SEM & Scanning Electron Microscope & heat generation due to the extensive use of fossil fuels, such \\
\hline $\mathrm{SO} 2$ & Sulphur Dioxide & as coal, oil, and natural gas in the sector $[5,6]$. This sector \\
\hline TIPS & Thermally Induced Phase Separation & alone has contributed to $40 \%$ of the total global emissions \\
\hline TSA & Temperature Swing Adsorption & [7]. Based on IEA [8], electricity and heat generation pro- \\
\hline VIPS & Vapor Induced Phase Separation & duced about $13,603 \mathrm{MtCO}_{2}$ in 2017 . As depicted in Fig. 1, \\
\hline & Mean Free Path & this amount was much higher than the other sectors $[8,9]$. \\
\hline
\end{tabular}

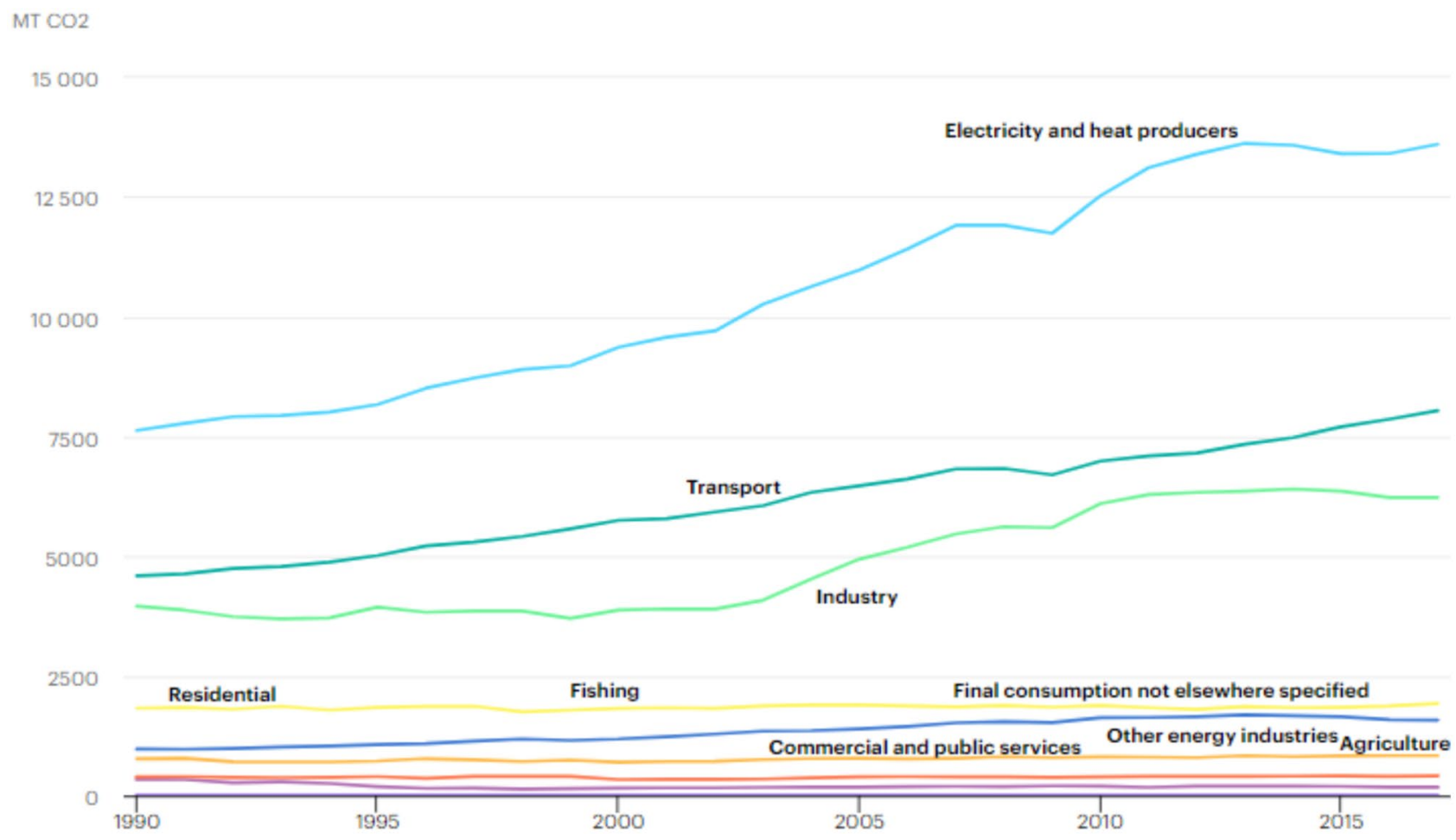

Fig. $1 \mathrm{CO}_{2}$ Emissions by Sector, World 1990-2017 [8] 
High emissions in electricity and heat generation sectors provide an opportunity to prevent $\mathrm{CO}_{2}$ emissions. Hence, this allows for the application of decarbonization approaches such as CCS to minimize $\mathrm{CO}_{2}$ emissions $[10,11]$.

\section{CCS technology}

$\mathrm{CO}_{2}$ is increasingly becoming a valuable commodity that has ignited interest surrounding carbon capture technologies [7]. Its exploitation may enhance industry value-chains and positively affect strategies for reducing $\mathrm{CO}_{2}$ emissions. An alternative to curb $\mathrm{CO}_{2}$ emissions is CCS. This method captures $\mathrm{CO}_{2}$ from a large source then stores it for commercial use or injection [4]. For instance, the oil and gas processes often re-inject $\mathrm{CO}_{2}$ into a reservoir for enhanced oil recovery [12]. This CCS application prevents $\mathrm{CO}_{2}$ emission, rerouting the GHG into the reservoir instead of emitting it as flue gas [13]. A typical power plant uses a simple scrubber to remove impurities before flue gas is released through a furnace stack, resulting in the release of gases with high $\mathrm{N}_{2}$ and $\mathrm{CO}_{2}$ concentrations. The lack of $\mathrm{CO}_{2}$ removal from residual gases in power plants resulted in an emission of $11.1 \mathrm{Gt}$ of $\mathrm{CO}_{2}$ in 2012 , which amounted to around a third of global $\mathrm{CO}_{2}$ emissions [14].

Furthermore, only a few power plants have started to reduce their $\mathrm{CO}_{2}$ emissions using CCS technologies [15].
$\mathrm{CO}_{2}$ is a by-product of combustion, and the choice of $\mathrm{CO}_{2}$ removal scheme should depend on the combustion process within the system. Presently, CCS systems are available in the market but are costly in general. A complete CCS system can cost up to $70-80 \%$ of a power plant [16]. There are three different carbon capture concepts: pre-combustion capture, oxyfuel capture, and post-combustion capture system, as illustrated in Fig. 2 [17, 18].

\section{Pre-combustion carbon capture}

In a pre-combustion carbon capture system, natural gas or coal transforms into syngas using oxygen $\left(\mathrm{O}_{2}\right)$ or steam reaction. This results in mostly carbon monoxide $(\mathrm{CO})$ and hydrogen $\left(\mathrm{H}_{2}\right)$ gases that are free from pollutants [19]. Next, the syngas undergoes a water-gas shift reaction to $\mathrm{CO}_{2}$ and creates more $\mathrm{H}_{2}$ through $\mathrm{CO}$ conversion [20]. The water-gas shift results in a higher concentration of $\mathrm{CO}_{2}$, which is then separated while the pure $\mathrm{H}_{2}$ produced is used for combustion and mostly generates $\mathrm{N}_{2}$ and water vapour [21, 22]. Integrated Gasification Combined Cycle (IGCC) power plants predominantly use this method to capture $\mathrm{CO}_{2}$ [23]. However, this method leads to an efficiency loss of $8 \%$ for coal-fired IGCC power plants due to the need for a gasification unit [24].

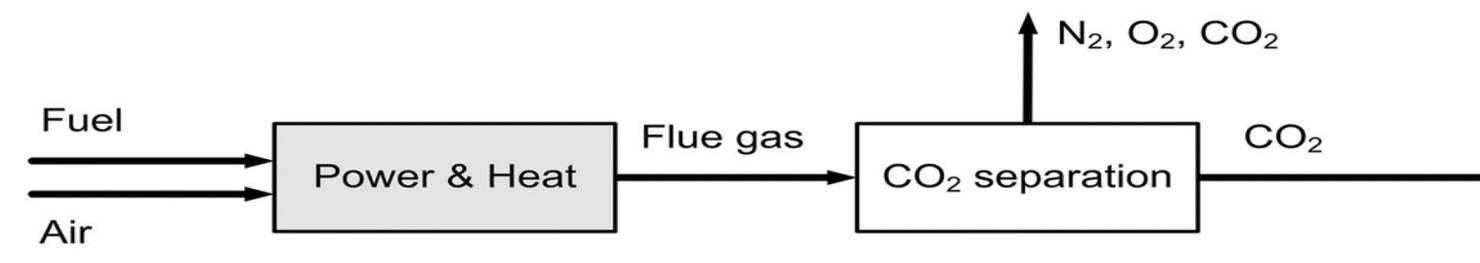

POST-COMBUSTION CAPTURE

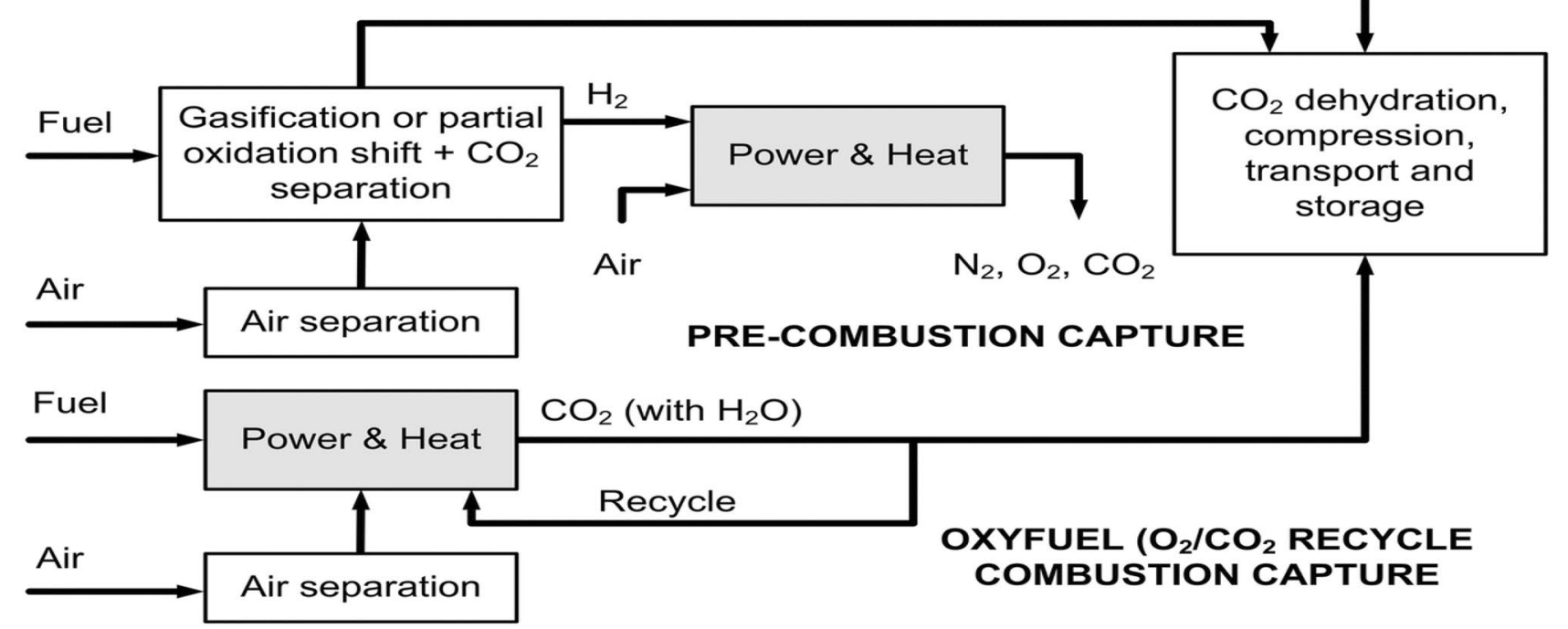

Fig. 2 Concepts of CCS [17] 


\section{Oxyfuel carbon capture}

The purpose of an oxyfuel carbon capture system is to achieve cleaner combustion using pure $\mathrm{O}_{2}$ instead of air to create flue gas rich in $\mathrm{CO}_{2}$ and water $\left(\mathrm{H}_{2} \mathrm{O}\right)$ in its vapor phase [25]. A portion of the flue gas is redirected into the furnace to control the flame temperature $[22,26]$. The residual $\mathrm{CO}_{2}$ and $\mathrm{H}_{2} \mathrm{O}$ in the remaining flue gases discharge via a purification process in cryogenic conditions [27]. The flexibility and customisability of the air separation unit (ASU) and supporting equipment, as well as its high purity (>99.9\%), make this method of CCS very efficient for coal-fired power plants [28]. However, the utility and energy costs remain a challenge for oxy-fuel combustion as it needs pure $\mathrm{O}_{2}$ supply and consumes a large amount of energy for its boilers and ASU $[11,22,25]$.

\section{Post-combustion carbon capture}

The post-combustion capture system captures $\mathrm{CO}_{2}$ from the typical flue gas and prevents its release into the atmosphere. In this system, the carbon capture process occurs after the combustion process, which presents a retrofitting option without any change required on the pre-existing process [ $[16$, $29,30]$. Additionally, the post-combustion scheme's advantage lies in the maturity of the processes involved, such as amine scrubbing (absorption), leading to $\mathrm{CO}_{2}$ purity higher than $99.99 \%$ [7]. However, the main limitation of this technology is the high energy load that often correlates with the cost accumulated from the solvent regeneration process and compression of $\mathrm{CO}_{2}[26,31]$. The low amount of $\mathrm{CO}_{2}$ levels in the combustion flue gas, typically less than $15 \%$, means that more energy is required to separate $\mathrm{CO}_{2}$ from flue gas [30, 32]. Furthermore, other technologies that are viable alternates to capture $\mathrm{CO}_{2}$ selectively are adsorption, cryogenic separation, or membrane separation [18].

\section{$\mathrm{CO}_{2}$ separation process}

The $\mathrm{CO}_{2}$ separation process consists of $75 \%$ of the overall CCS costs and $50 \%$ of the electricity production costs [33]. These figures vary for the various CCS systems; cost reduction for $\mathrm{CO}_{2}$ separation remains the most significant dispute for CCS to be adopted in the energy sector [27]. Currently, there are wide varieties of processes for extracting $\mathrm{CO}_{2}$ from gas streams. Physical or chemical properties are the driving force of these processes, such as absorption, adsorption, cryogenic, and membranes [34, 35].

\section{Absorption process}

One of the widely used technologies to separate $\mathrm{CO}_{2}$ from power plant exhaust gas is absorption stripping [36]. In this approach, the $\mathrm{CO}_{2}$ in the flue gas is cooled to about $320^{\circ} \mathrm{K}$. Then, it feeds into a column stripper where it comes into contact with a liquid solvent (absorbent), absorbing $\mathrm{CO}_{2}$ from the flue gas mixture. The solvents used in this method are either physical or chemical solvents. The physical solvent method uses organic solvents to mechanically absorb the components without reacting while using pressure and temperature as a driving force [37]. Regarding chemical absorption, it mostly relies on acid-base reactions by applying alkaline solvents [29].

Amine-based solvents such as mono-ethanolamine (MEA) have been widely utilised in the industry for over 60 years and have become a highly developed and promising product to date [7]. Many companies have already installed the MEA absorption system in full-scale for $\mathrm{CO}_{2}$ separation in fuel power plants. For example, the Shell gas-fired power plant in Norway and the RWE coal-fired power plant in the United Kingdom produces $860 \mathrm{MW}$ and $500 \mathrm{MW}$ of electricity, respectively [38]. However, these absorption processes are non-economical as they require high energy input and large-size equipment. A schematic of a typical adsorption process for $\mathrm{CO}_{2}$ separation is presented in Fig. 3 [39].

Though absorption is currently used widely in the industry, a few disadvantages exist in the system. Firstly, the high corrosion rate of equipment used in the absorption of $\mathrm{CO}_{2}$ [29]. Besides that, solvent degradation requires more fresh solvent feed, resulting in increased costs of the products and disposal of degraded solvents. The disposal of solvents would result in more pollution to the surroundings [38]. Additionally, this separation technique also involves high energy consumption due to the absorbent regeneration stage that requires high-temperature operations [40].

\section{Adsorption process}

Another approach to separating $\mathrm{CO}_{2}$ is adsorption. The adsorbents used in this process are in solid form rather than in liquid form. The use of a solid adsorbent is to accumulate all the $\mathrm{CO}_{2}$ that passes through its surface [16]. Similarly, the adsorption method has two critical stages: adsorption and adsorbent regeneration, which is more commonly called desorption. The removal of the desired components from flue gas occurs in the adsorption stage using solid adsorbents such as zeolites, lithium zirconate, silica gel, activated carbon, and molecular sieves [37, 40]. The used adsorbents with high contents of the desired components are regenerated and recycled in the desorption stage [40].

There are two variations of adsorption used to remove and store adsorbed $\mathrm{CO}_{2}$. These are temperature swing adsorption (TSA) and pressure swing adsorption (PSA) [41]. PSA is mostly used as $\mathrm{CO}_{2}$ recovery technology for power plants with high efficiency ( $>85 \%$ ) [41]. This process involves the selective adsorption of $\mathrm{CO}_{2}$ on the surface of 
Fig. 3 Typical $\mathrm{CO}_{2}$ Absorption Process [39]

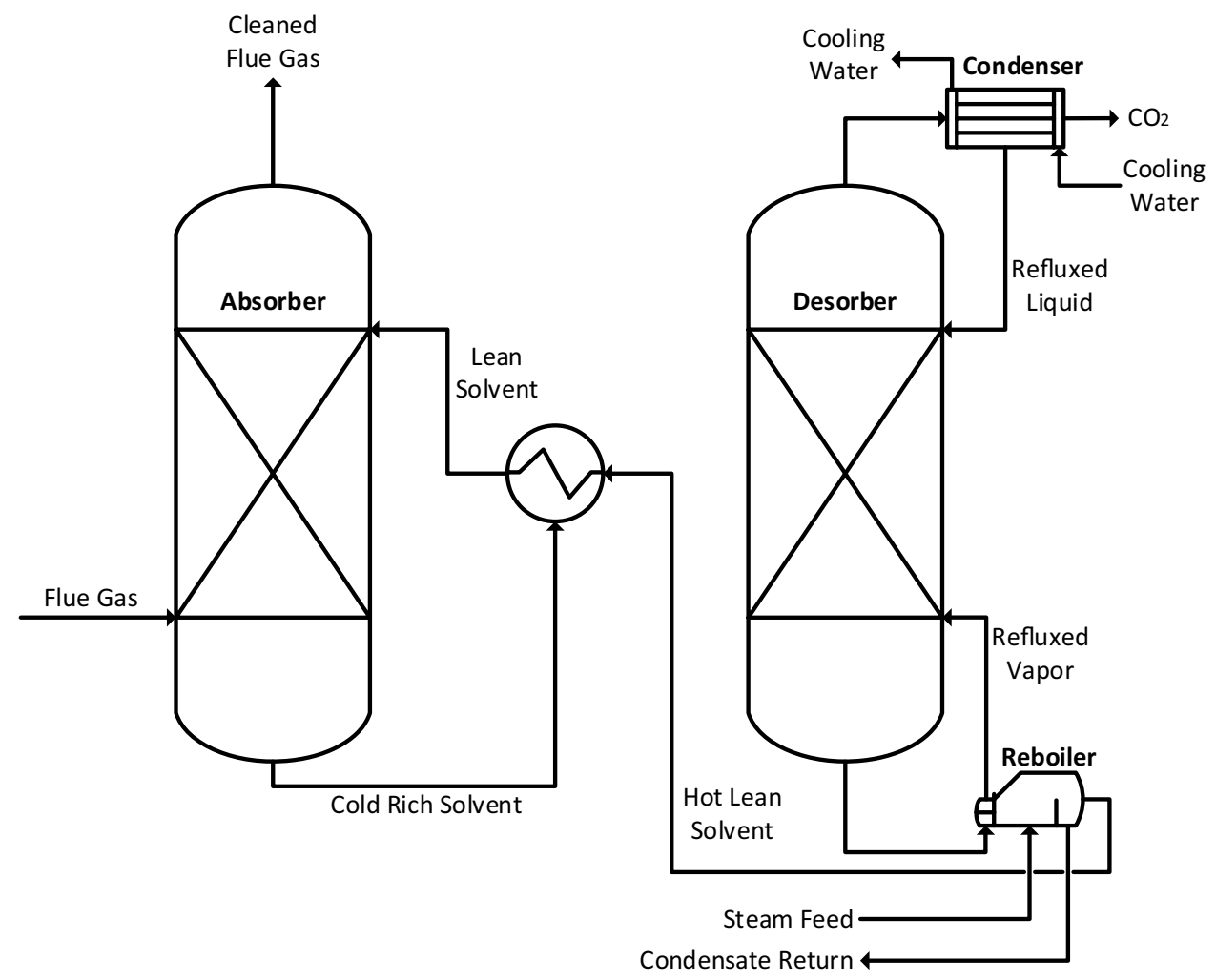

a solid adsorbent at a higher pressure. Further, it swings to a lower pressure to regenerate the adsorbents and release $\mathrm{CO}_{2}$ for subsequent transport [42]. As temperature does not change dramatically throughout the process, thermal and mechanical energy consumption is considerably lower than traditional TSA. Thus, PSA is more practical for industrial purposes [43]. In TSA, removing the absorbed $\mathrm{CO}_{2}$ from the adsorbents involves increasing the device temperature by hot air or steam injection. The adsorbents typically take a longer time to regenerate compared to PSA, but higher $\mathrm{CO}_{2}$ purity $(>96 \%)$ and higher recovery $(>80 \%)$ is achieved [44]. However, the TSA process requires more significant amounts of energy for the $\mathrm{CO}_{2}$ adsorption stage, as it uses a high-temperature adsorbent [45]. The cost to operate a typical TSA process is estimated to be between US\$ 80-150 per tonne of $\mathrm{CO}_{2}$ captured [46]. Scaling up the adsorption process is also proven to be a challenge [47].

\section{Cryogenic separation process}

As for the cryogenic $\mathrm{CO}_{2}$ removal process, the gas mixtures separation theory uses fractional condensation where the separation occurs at low temperatures [48]. This system is typically preferred when there is high $\mathrm{CO}_{2}$ content in the stream, with more than $90 \%$ [27]. The process involves chilling of flue gases at very low temperatures to liquefy $\mathrm{CO}_{2}$ and ease the subsequent processes [49]. The cryogenic separation allows the direct production of pure liquefied
$\mathrm{CO}_{2}$, making it more convenient for transport and storage [29]. Simplicity is another advantage for this technique as it does not require any additional solvent or other components. Furthermore, the simple principles of the process make it easy to scale-up [50].

While cryogenic separation has many advantages, it requires enormous power or energy for the refrigeration (chilling) stage and operational problems due to $\mathrm{CO}_{2}$ solidification [51]. Incorporating gas hydrates (Fig. 4) for the sequestration of $\mathrm{CO}_{2}$ can mitigate this problem [52]. This process includes a second stage where the residue of $\mathrm{CO}_{2}$ from the cryogenic phase of condensation is solid hydrates that can easily be collected. This method decreases the energy required for feed gas cooling from the process streams [52].

\section{Membrane separation process}

Based on above, complex and costly operations are often associated with other $\mathrm{CO}_{2}$ removal technologies. Hence, membrane technology is increasingly becoming an innovation that can compete against these technologies [53]. Membrane technology meets the general low-cost requirements for $\mathrm{CO}_{2}$ removal [54]. Using a membrane with high selectivity, $\mathrm{CO}_{2}$ separates from flue gas without needing a high concentration of $\mathrm{CO}_{2}$ at the inlet [34].

A membrane is a semi-permeable barrier and has numerous transport mechanisms to aid in the recovery 
Fig. 4 Utilisation of Gas Hydrate Formation for Cryogenic Separation of $\mathrm{CO}_{2}[52]$

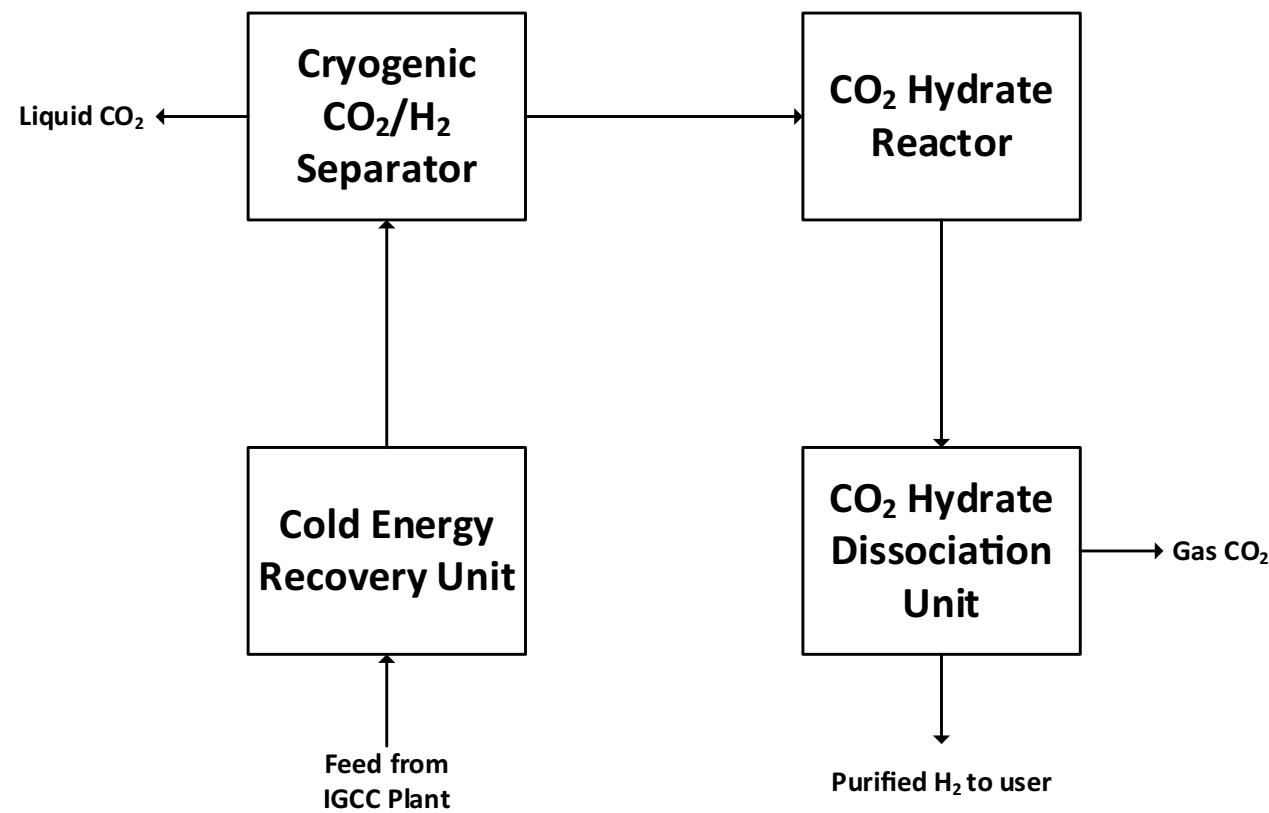

of specific components from inlet gas streams [55]. This technology shares a similar role as filters, where it only allows particular components to flow through. As a result, it produces a permeate or retentate stream with a high content of the desired component [56].

In a membrane, a pressure gradient induces the gas separation process. The permeate-side stream is normally open to the atmosphere, and the feed side carries the pressure from previous processes [57]. The component gases then flow from the side with higher pressure to the side with lower pressure. Compared to other approaches, membrane separation technology is a more straightforward and better energy-saving process, suitable for separating $\mathrm{CO}_{2}$ [58]. This approach does not require a regeneration process as it does not use any separating agent. As a membrane separator is a piece of static equipment, the requirement for maintenance is very minimal [59]. Compared to other traditional separation methods, the capital cost is relatively lower as additional equipment, such as a heat exchanger, is not required to be installed. Therefore, this process saves more energy as phase transformation is not needed [49].

Moreover, mild conditions make this process relatively easy to control and operate, while its non-complex process makes it convenient to scale-up [29]. A notable advantage of membrane separation is its high separation efficiency, whereby it is common to achieve $80 \%$ purity of the desired product. Examples of its success can be seen in studies by Gielen [60] and Audus [61]. They recorded their success of achieving 82 to $88 \%$ efficiency for $\mathrm{CO}_{2}$ separation when utilising the recently adapted technology of membrane separation $[16,60,61]$.
Despite these advantages, membrane technology has its drawbacks. This technology is still in unknown territory compared to other conventional technologies as it is not mature yet. It is also difficult to gain more experience using this technology in a large-scale process as many companies prefer a more proven and conventional process [62]. Lifespan is also a significant issue with membrane technology due to fouling [63]. Based on Lu et al. [64], the Palladium membranes have a short lifespan; that often only requires months before a new replacement, which subsequently results in additional costs [64].

Further, selectivity and the required purity of the permeate highly influences the energy consumption of a membrane. On some occasions, one membrane is insufficient to achieve the required purity, which may require multiplestage membranes or a membrane with larger areas. Therefore, poor-performing membranes can result in more costs through energy usage and replacements [34].

Nevertheless, in recent years developments in pilot-scale membrane plants have grown, particularly for post-combustion carbon capture [65]. Hägg et al. [66] reported that a pilot post-combustion membrane plant installed at a Northern Cement factory in Norway could capture $70 \%$ of $\mathrm{CO}_{2}$ from low $\mathrm{CO}_{2}$ content (17\%) flue gas in a single-stage setup. The plant uses polyvinylamine (PVAm) based hollow fibre membrane modules (up to $18 \mathrm{~m}^{2}$ ) fabricated by Air Products [66]. Similar pilot-scale PVAm hollow fibre membrane modules were applied to separate real flue gas from a propane burner at the SINTEF Tiller plant in Trondheim (Norway), where $\mathrm{CO}_{2}$ purity reached $60 \%$ in the permeate stream from a feed flue gas containing $9.5 \%$ of $\mathrm{CO}_{2}$ [67]. However, from a process engineering perspective, the future development 
of membrane technology in post-combustion $\mathrm{CO}_{2}$ capture should be focused on future $\mathrm{CO}_{2} / \mathrm{N}_{2}$ selective membranes with selectivity higher than 50 and $\mathrm{CO}_{2}$ permeance higher than $4000 \mathrm{GPU}$. This precise membrane specification could offer a $\mathrm{CO}_{2}$ capture cost lower than US\$ 15 per ton of $\mathrm{CO}_{2}$, which is below the US Department of Energy's (DOE) targeted goal of US\$20\$per ton $\mathrm{CO}_{2}[67,68]$. Merkel et al. [68] suggested that future developments in membrane separation should focus on enhancing permeability of the membrane as long as its $\mathrm{CO}_{2} / \mathrm{N}_{2}$ selectivity is above $30[65,68]$.

Furthermore, other operational properties should also be considered, such as chemical stability, heat resistance, lifespan, and durability against plasticisation [29]. These properties are usually affected by different membrane materials, which could be inorganic or organic [69]. Similarly, the membrane structure, whether non-porous or porous, can also alter its properties and gas separation performance [70].

\section{Membrane morphologies}

The separation properties of a membrane are affected by the type and characteristics of the fabrication material [71]. There are primarily two types of materials that make up a membrane, either polymeric; or inorganic [29]. Both types of membranes can be categorised into dense, porous, and composite based on their morphology, as stated in Fig. 5 [72].

\section{Dense membranes}

Dense homogeneous polymer membranes are only practical when the process requires highly permeable membranes, often requiring a minimum membrane thickness to be mechanically stable [72]. The permeate that flows through the membrane is usually very small, so a minimum thickness is necessary to ensure mechanical stability [73]. The dominant transport mechanism through the dense polymeric membranes is solution diffusion. In contrast to porous membranes, permeation of components in dense membranes is indirect. The most beneficial aspect of the solution-diffusion mechanism is the ability to adjust the permeation of the various components throughout the separation process [74]. This mechanism has three sequential stages. The first stage is the

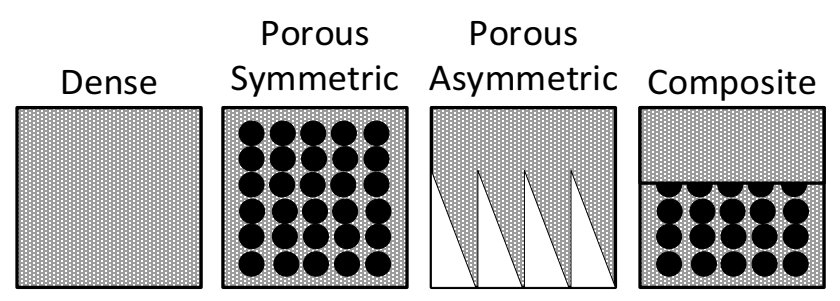

Fig. 5 Classification of Membrane Morphology [72] adsorption of the desired component on the feed side of the membrane. Next is the transfer of molecules through diffusion through the polymer matrix. Lastly, desorption occurs where the desired components evaporate on the surface of the membrane's permeate side [75]. The driving forces of this system are the variation in thermodynamic behaviours around the membrane and the magnitude of the gas-polymer interactions [76]. Concentration variances exist due to a gradient in thermodynamic activity, as presented in Fig. 6 [75, 77].

In this mechanism, permeability $(\mathrm{P})$ defines the efficiency of a membrane, as shown in Eq. 1 [78]:

$P=D \times S$

where ' $\mathrm{D}$ ' is the diffusivity coefficient, while ' $\mathrm{S}$ ' is the solubility coefficient. The ratio of the permeabilities mostly describes the selectivity $(\alpha)$. Equation 2 represents this ratio [78].

$\alpha_{A / B}=\frac{P_{A}}{P_{B}}$

Additionally, a well-known equation to calculate the gas flow rates, $\mathrm{Q}$ is shown in Eq. 3.

$Q=\frac{P A_{\left(p_{1-} p_{2}\right)}}{l}$

where ' $p_{1}$ ' and ' $p_{2}$ ' are the feed and permeate side pressures respectively, 'A' the membrane area, and ' $l$ ' the thickness of membrane [78].

\section{Porous membranes}

Typically, porous membranes come in one of two forms, symmetric (isotropic) or asymmetric (anisotropic) membranes [70]. Porous membranes with a consistent structure throughout their whole area fall under the symmetric porous membranes category. On the other hand, membranes with a gradient in their structure are classified under the asymmetric membrane category [72]. Further, pore sizes are also useful for categorizing porous membranes, as summarised in Table 1 [79].

In addition to characterisation, pore sizes heavily affect the gas transport mechanisms through the membrane [65]. In a porous membrane, the transport mechanism is highly dependent on the pore size compared to the mean free path of molecules and the size of the transported molecule. The transport mechanisms in a porous membrane follow pore flow models, such as Knudsen diffusion, Poiseuille flow, molecular sieving, surface diffusion, or capillary diffusion [81].

Knudsen diffusion occurs typically in a convective flow of a porous membrane. Generally, it takes place in a small 
Fig. 6 Illustration of Solution Diffusion Transport Mechanism [77]

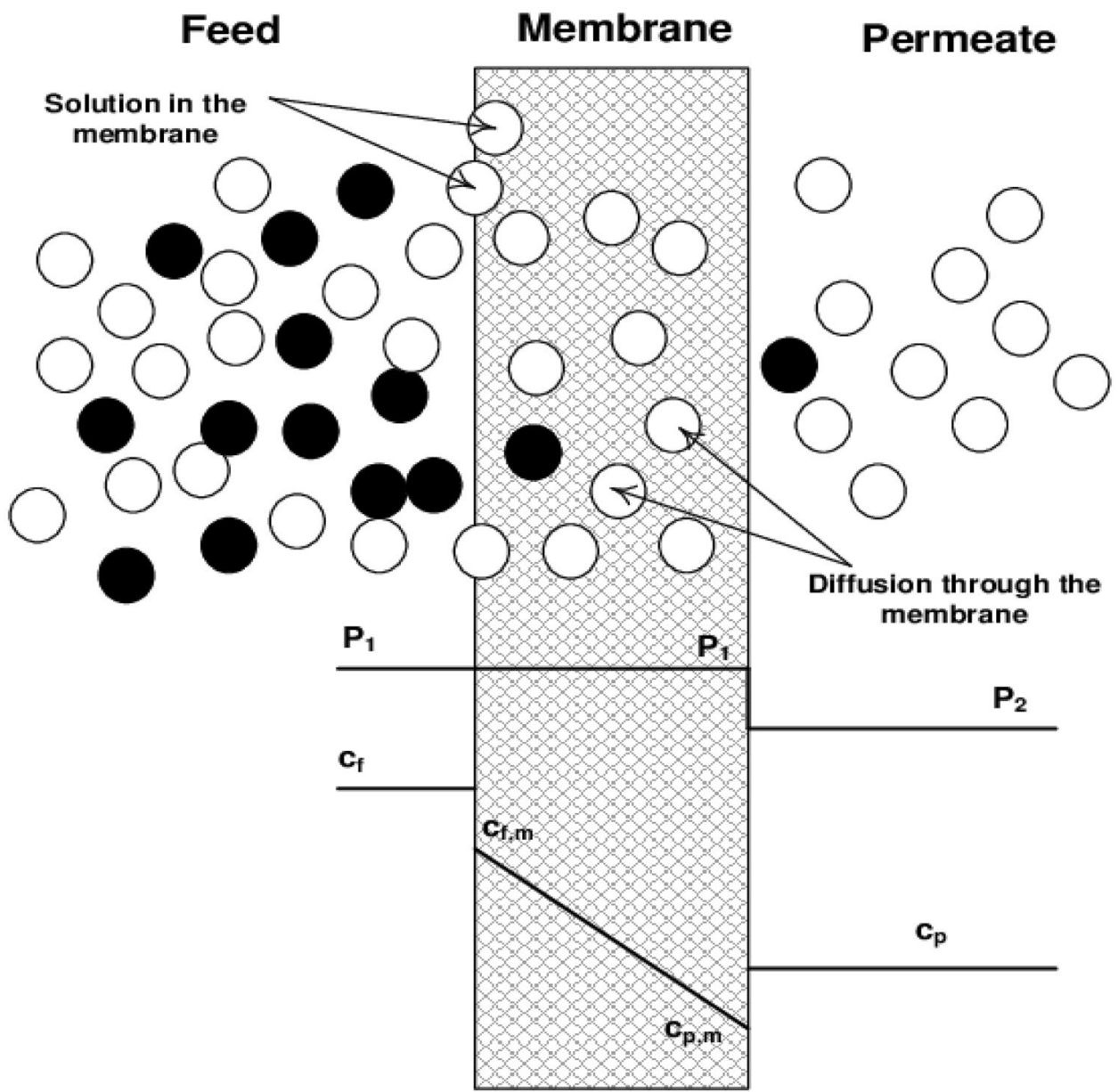

diameter of the long pore where the frequent collision of molecules against the membrane walls occurs [82]. This mechanism is likely to happen in a membrane with pore sizes lower than the mean free path $(\lambda)$ of the gas molecules, where $\lambda$ is calculated by Eq. 4 [76].

$\lambda=\frac{3 \eta \sqrt{\pi R T}}{4 p M}$

where ' $\eta$ ' is gas viscosity, ' $p$ ' is pressure, ' $T$ ' is temperature, ' $R$ ' is gas constant, and ' $M$ ' is the molecular weight. If the membrane pore size is smaller than its mean free path $(\mathrm{r} / \lambda<0.05)$, molecules tend to move independently and frequently collide with the membrane walls than amongst themselves. The collisions result in a velocity gradient

Table 1 Pore Categories for Porous Membranes

\begin{tabular}{lll}
\hline Category & $\mathrm{dp}$ & Ref \\
\hline Macroporous & Larger than $50 \mathrm{~nm}$ & {$[79]$} \\
Mesoporous & $2 \mathrm{~nm}$ to $50 \mathrm{~nm}$ & {$[72]$} \\
Microporous & $1 \mathrm{~nm}$ to $2 \mathrm{~nm}$ & {$[70]$} \\
Nanoporous & Smaller than $1 \mathrm{~nm}$ & {$[80]$} \\
\hline
\end{tabular}

between molecules of different components, which would then be a medium for gas separation. The lighter components are more likely to go through the membrane, while the heavier components are less likely to pass. The molar flux is calculated by Eq. 5 [76]:

$G_{K n}=\frac{8 r\left(p_{1}-p_{2}\right)}{3 L \sqrt{2 \pi M R T}}$

where ' $\mathrm{L}$ ' is the pore length, ' $\mathrm{r}$ ' is the pore radius, ' $\mathrm{p}_{1}$ ' and ' $\mathrm{p}_{2}$ ' are the partial pressure of the feed and permeate gases, respectively. Additionally, prediction of selectivity for the Knudsen mechanism uses square-roots from the molecular weight ratios, as shown in Eq. 6 [76]:

$\alpha_{K n}=\sqrt{\frac{M_{j}}{M_{i}}}$

Poiseuille flow occurs when the driving force for the diffusion is the pressure gradient between the feed and the permeate side. It usually happens with pore sizes of around $200 \mathrm{~nm}$ to $3,000 \mathrm{~nm}$ or when the membrane pore sizes are much greater than $\lambda(r / \lambda>3)$. It is also known as convective 
diffusion, which operates opposite to Knudsen diffusion. In contrast to Knudsen diffusion, this mechanism depicts gas diffusions through the molecular collisions instead of collisions with the pore walls. In Poiseuille flow, all the component molecules pass through the pores by an average drift velocity, independent of the shape, mass, and size of the molecules [74]. The molar flux is represented in Eq. 7, illustrating the Poiseuille flow mechanism [76, 82].

$G_{P}=\frac{r_{2}\left(p_{1}-p_{2}\right)}{16 L 2 \mu R T}$

The molecular sieving mechanism takes place in membranes with small pore sizes $(<7 \AA$ ). For it to occur, the membranes must possess pore sizes between the molecular sizes of the gas pair that are about to be separated. Thus, separation occurs through the differences in the size of molecules where only gas molecules with an appropriate range of kinetic diameters can permeate, preventing larger molecules from passing through the pores [76].

The surface diffusion mechanism usually exists in porous membranes where the permeating molecules are strongly attracted to the membrane surface. The absorption of molecules occurs along the length of the pore walls [76]. The driving force for the separation using this mechanism is the difference in the affinity of the pore walls towards different molecules [82].

Capillary condensation transport occurs at specific critical relative pressures in which the condensed gas has filled the pores and excludes other components from entering the pores [76]. In this mechanism, the separation of gas molecules occurs by partial condensation of any one component from the gas mixtures. For this mechanism to happen, it usually requires the mesoporous pore (pore diameter $>3.0 \mathrm{~nm}$ ) to facilitate condensation [76]. This mechanism can achieve high selectivity as the flow of non-condensable gas molecules is blocked [82]. Also, both surface diffusion and capillary diffusion can coincide due to similar underlying conditions [83].

\section{Composite membranes}

Another critical group of membranes in the industry is composite membranes. This kind of membrane consists of a thin and dense selective surface above a supporting porous layer
[72]. Membranes in this category are typically made up of either organic (polymeric) material, inorganic material, or both (mixed matrix), depending on their purpose [79]. The transport mechanism in composite membranes is determined using the Resistance model as it consists of several barrier layers with a distinct nature [84]. Unlike porous or dense membranes, the composite membrane has an apparent discontinuity at the boundary of two adjacent barrier layers. The discontinuity can arise from the chemical structure or in the morphology of the material [85]. In this case, the permeation rate, $\mathrm{Q}_{\mathrm{i}}$, can be calculated as a function of the driving force, which is the pressure difference, $\Delta \mathrm{p}$, and the resistance to the flow, $\mathrm{R}^{\prime}$ as shown in Eq. 8 [84].

$Q_{i}=\frac{\Delta p}{R^{\prime}}$

The connection between resistances in composite membranes uses the following configurations: series, parallel, and two resistance arms [85]. Two resistances are connected in series whenever two layers of membranes are combined in a series, as shown in Fig. 7(a). Two resistances are connected in parallel whenever distinct materials exist and secured on the same layer of the membrane's surface, as shown in Fig. 7(b). The parallel combination of two resistance models is useful when a homogeneous film of relatively high permeability is laminated on top of the membrane, as shown in Fig. 7(c).

\section{Membrane materials}

\section{Inorganic membrane}

Metals, rigid polymers (ceramics), or pyrolysed carbons are common fabrication materials of an inorganic membrane. The purpose of using metals and ceramics in fabricating an inorganic membrane is to add mechanical strength with minimum resistance for mass transfer [86]. Besides, it promotes membrane surface interaction with the desired component, which increases permeation efficiency [40]. This type of membrane is typically stable and offers high thermal resistance for $\mathrm{CO}_{2}$ separation from hot gases. However, selectivity and permeability are low compared to other membrane varieties, which require further development [29]. Regardless of
Fig. 7 Transport Resistance in Composite Membranes [85]
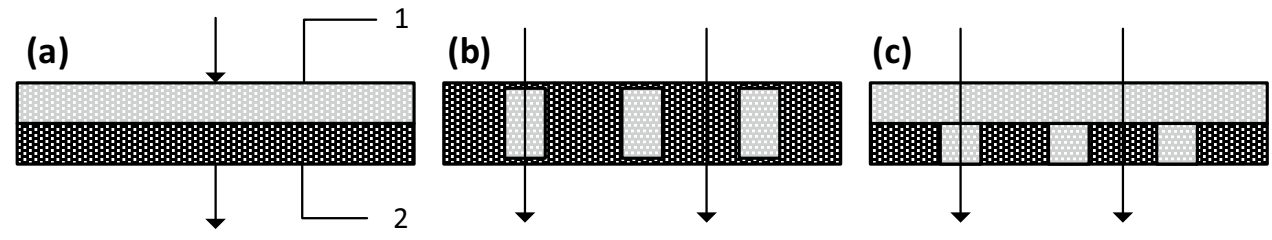
the potential offered by inorganic membranes, the technology tends towards high manufacturing costs. Furthermore, the requirement of complex fabrication techniques often limits its application [87]. Inorganic membranes also face durability issues as they are fragile and brittle, requiring extra attention when handling [37].

\section{Mixed matrix membrane (MMM)}

The notion of MMM was discovered in the early 1970s when Paul and Kemp found out that incorporating 5A zeolite to a polydimethylsiloxane (PDMS) membrane leads to a large increase in $\mathrm{CO}_{2}$ diffusivity along with an improved separation performance. Their findings motivated scientists to further their research and exploit the concept [88]. The MMM comprises of organic polymer matrix with inorganic filler particles. The coalition of these two different membrane materials results in a composite membrane [89]. The two materials create two phases: the bulk phase (polymeric) and the dispersed phase (inorganic). Generally, materials used as inorganic fillers in MMM are zeolite, silica, or carbon nanotubes (CNTs) [90].

In the MMM, gas separation efficiency improves due to the superior adsorptive properties of inorganic fillers added into a polymeric membrane [91]. Researchers focused on composite membrane structures by combining different fillers that improved the surpass of the separation performance compared to that of just one component [89]. However, this membrane may cost around 10-100 times more than neat membranes and is not preferable in situations where neat/ polymeric membranes cannot satisfy separation requirements [92].

\section{Polymeric membrane}

Glassy or rubbery organic polymers are the building blocks of a polymeric membrane [93]. Polymeric membranes tend to display a trade-off situation between permeance and ideal selectivity. An increase in ideal selectivity of gas pair results in a decrease in permeance and vice versa [94]. Rubbery polymeric membranes often possess a soft, elastic, flexible membrane structure, which can operate beyond its glass-transition temperature [95]. Generally, rubbery membranes exhibit properties such as high permeance and low ideal selectivity [96].

Consequently, its low selectivity will lead to lack of application in the industry; while its glassy membrane counterpart is widely used [95]. A glassy membrane tends to be more durable due to its rigidity in contrast to rubbery membrane, as it displays properties of high selectivity but low gas permeability [94]. Some commonly used glassy membranes that are suitable for $\mathrm{CO}_{2}$ separations are polysulfone (PSF), polyethersulfone (PES), polyimides (PI), polyamidebethylene oxide (Pebax $\left.{ }^{\circledR}\right)$, and cellulose acetate (CA) [97].

Polymeric membranes often have lower capital costs when compared to inorganic membranes or MMMs. Additionally, polymeric membranes have higher mechanical stability and are easier to fabricate [34]. However, polymeric membranes often have low thermal stability, causing unstableness at high temperatures [29]. Nevertheless, polymeric membranes are highly preferable for $\mathrm{CO}_{2}$ separations than inorganic membranes and MMMs due to low capital costs, leading to a broader industrial application [49]. The advantageous and disadvantageous aspects of polymeric, inorganic, and MMMs are summarised in Table 2 [71].

Table 2 Summary of Advantages and Disadvantages of Different Types of Membranes [71]

\begin{tabular}{|c|c|c|}
\hline Type of Membrane & Advantages & Disadvantages \\
\hline Inorganic Membranes & $\begin{array}{l}\text { - Excellent mechanical, chemical and thermal resistance } \\
\text { - Variable pore size } \\
\text { - Small upper-bound trade-off } \\
\text { - Able to withstand harsh conditions }\end{array}$ & $\begin{array}{l}\text { - Brittle } \\
\text { - High production cost } \\
\text { - Difficult to scale-up }\end{array}$ \\
\hline MMM & $\begin{array}{l}\text { - Improved mechanical and thermal properties } \\
\text { - Lower plasticization compared to polymeric membranes } \\
\text { - Suitable for high pressure } \\
\text { - Lower energy requirement } \\
\text { - Separation performance follows both inorganic and polymeric } \\
\text { membrane properties }\end{array}$ & $\begin{array}{l}\text { - Brittle at high concentration of } \\
\text { organic fillers } \\
\text { - Chemical and thermal stability } \\
\text { dependent on polymer matrix } \\
\text { - More expensive than polymeric } \\
\text { membranes }\end{array}$ \\
\hline Polymeric Membranes & $\begin{array}{l}\text { - Simple fabrication } \\
\text { - Low Production Cost } \\
\text { - Mechanically stable } \\
\text { - Easy Scale-Up }\end{array}$ & $\begin{array}{l}\text { - Low thermal and chemical stabil- } \\
\text { ity } \\
\text { - Plasticization } \\
\text { - Invariable pore sizes } \\
\text { - Upper-bound Trade-off }\end{array}$ \\
\hline
\end{tabular}




\section{Issues concerning polymeric membrane}

Besides all the advantages that polymeric membranes offer, there are still several issues to address to achieve a highly efficient membrane with a more stable performance. These issues include the upper bound trade-off between $\mathrm{CO}_{2}$ permeance and $\mathrm{CO}_{2} / \mathrm{N}_{2}$ ideal selectivity and plasticisation [98].

\section{Permeability-selectivity trade-off}

One of the main issues associated with polymeric membranes is the trade-off between selectivity and permeation. The two parameters possess an inverse relationship where membrane selectivity for different gas-pairs can increase when the gas permeance is coherently decreasing. This notorious phenomenon is often addressed as the trade-off between these two parameters [99]. Therefore, a breakthrough occurred when Robeson [100] proposed an empirical relationship of upper-bound between both the selectivity and the permeability, as illustrated in Eq. 9, to formulate a point of reference for membrane performance [100].

$P_{i}=k \alpha_{i j}^{n}$

where ' $P_{i}$ ' and ' $\alpha_{i j}$ ' respectively stand for permeability and selectivity, while ' $k$ ' and ' $n$ ' are the values calculated for the upper bound linear relationship for different gas pairs [100]. Freeman [101] further studied the upper-bound curves, such as the one shown in Fig. 8, where the upper-bound curves are obtained from previous studies from Robeson [100] with specific references and plotted the data as $\alpha_{i j}$ versus $\log P_{i}$. His study suggested that more attention should be put on increasing selectivity through chain rigidity and the interchain spacing in order to exceed the upper-bound successfully [101]. The $\mathrm{CO}_{2} / \mathrm{N}_{2}$ upper-bound curve in Fig. 7 was established in 2008 rather than 1991 due to insufficient data to illustrate the correlation [102].

\section{Membrane plasticization}

Plasticisation is the absorption of small chemically benign molecules that migrate between molecular chains, causing a membrane to lose stiffness [103]. The occurrence of plasticisation depends on the volume of gas entering the polymer matrix and Henry's Law. Thus, it is significantly affected by partial pressures. Irregular behaviour where permeance increases with increasing partial pressure is usually a sign of plasticisation [104].

Other than the trade-off issue, plasticisation also has a significant negative effect on $\mathrm{CO}_{2} / \mathrm{N}_{2}$ separation. It usually occurs when there is a high content of $\mathrm{CO}_{2}$ in the feed gas, which affects the amount of dissolved gas within the polymeric matrix [105]. This particular plasticisation triggers a trade-off phenomenon where $\mathrm{CO}_{2}$ permeance continuously increases and selectivity declines as a function of pressure [82]. This phenomenon also occurs when the partial pressure of the penetrant elevates and exceeds a specific point. This point is commonly known as plasticisation pressure (Fig. 9) [104]. Consequently, this tendency results in a lack of selectivity of the membrane, which impairs its efficiency.
Fig. 8 Robeson's Upper-Bound Correlation Plot [102]

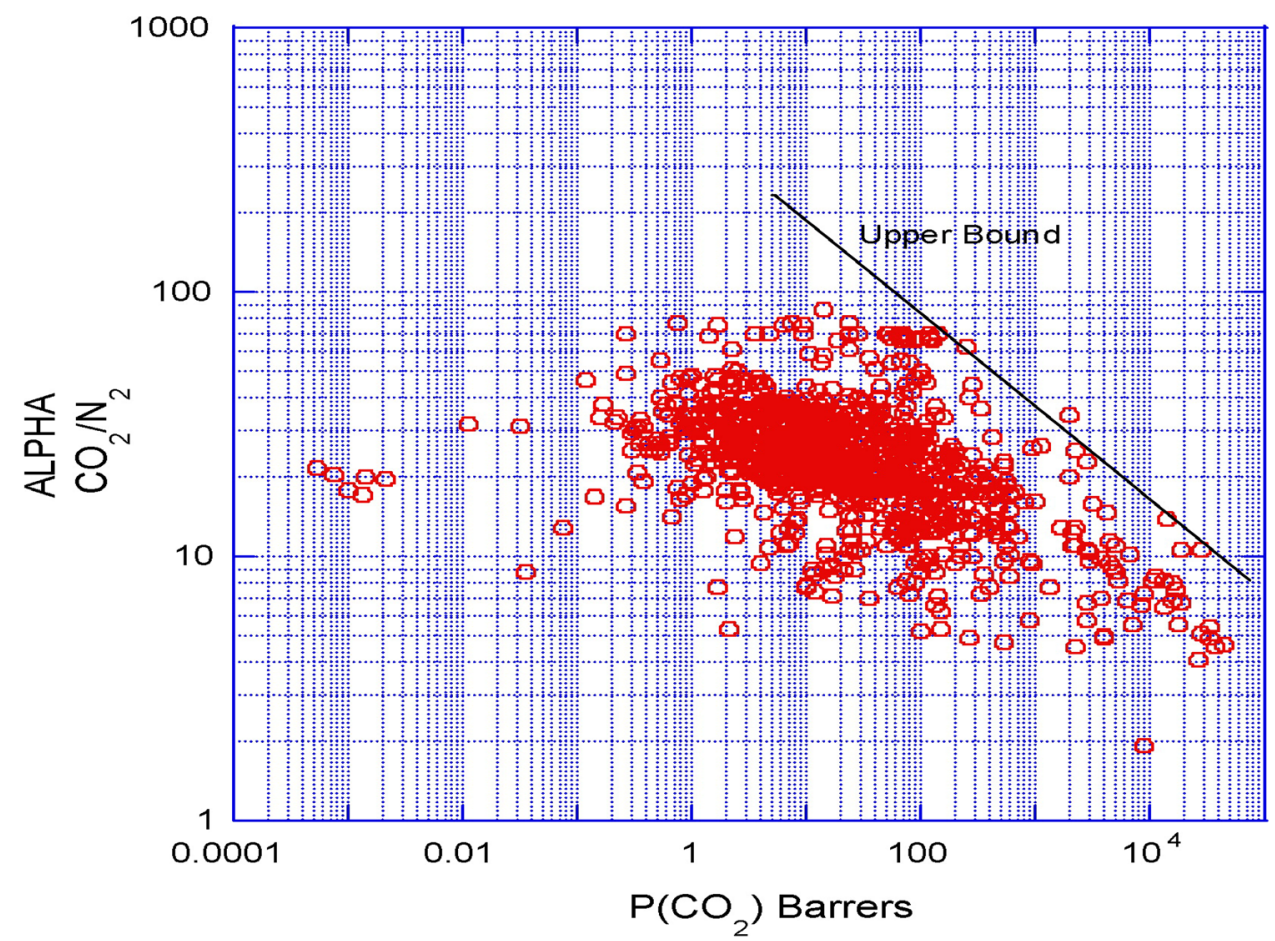


Fig. 9 Permeability vs. Pressure graph to determine Plasticisation Pressure [104]

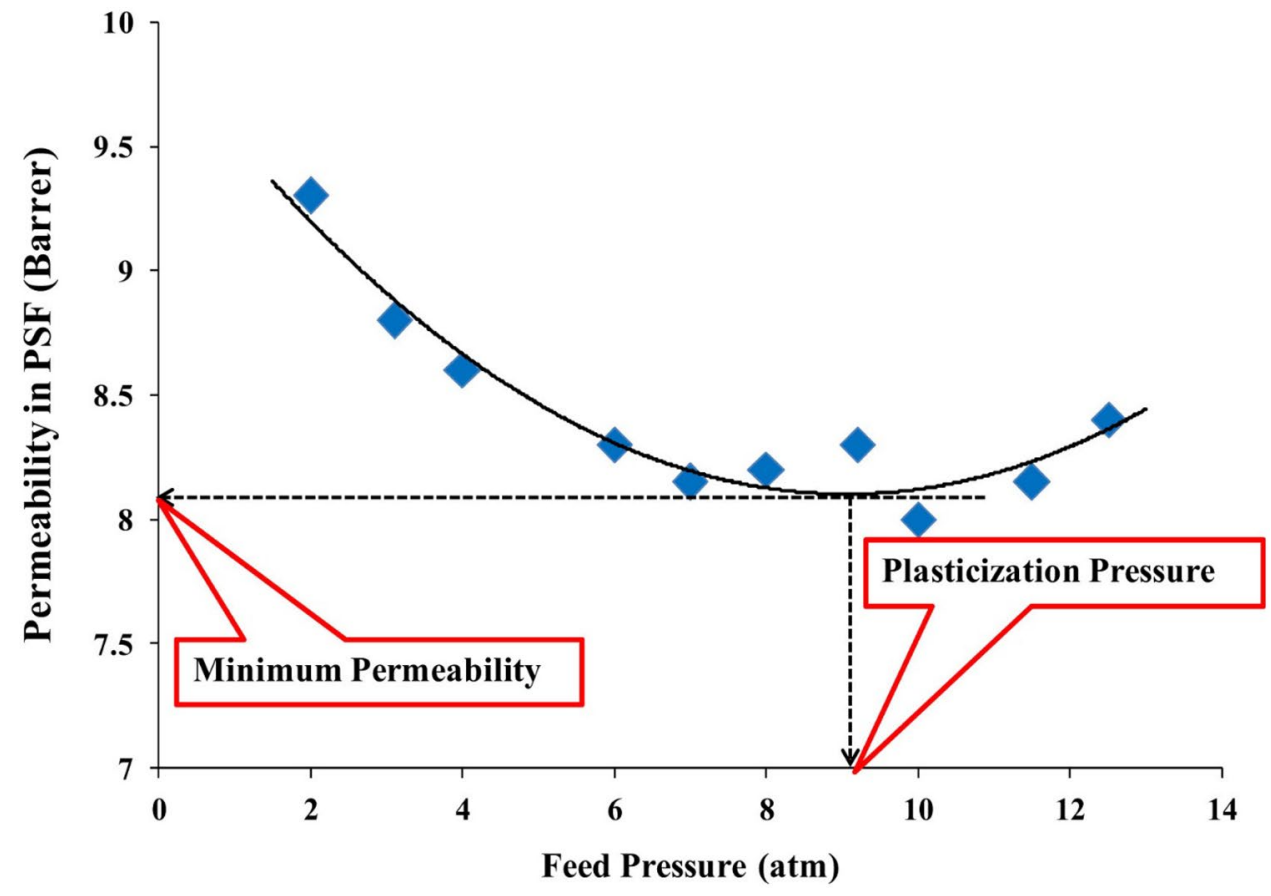

Currently, a few approaches exist to subdue plasticisation caused by $\mathrm{CO}_{2}$, such as bonding, polymer blending, thermal treatment, and incorporation of inorganic fillers [99].

\section{Blend polymeric membranes}

Polymer blends combine multiple polymers into a new product with enhanced properties [106]. A blend membrane with the desired properties is a combination of different polymers with distinctive physicochemical and separation properties [93]. However, polymer blends tend to be thermodynamically immiscible [107, 108]. Miscibility of polymers significantly affects the morphology and the specific volume fraction within the blend membrane. Consequently, this also affects its performance [109]. Soleimany, Hosseini [110] also stated that blending a polymer susceptible to plasticisation with one of a lower tendency towards plasticisation can reduce the overall plasticisation tendency of a membrane [110]. The blending of rubbery PEG and glassy PSF polymers results in a final membrane with properties beyond the upper bound for $\mathrm{CO}_{2} / \mathrm{N}_{2}$ in Robeson's plot [111]. Jujie et al. [112] studied the performance of PEG/PSF blend membranes [112]. They found that a drop of $36 \%$ in the $\mathrm{CO}_{2}$ permeance occurred due to encapsulation of the PSF chain by the PEG chain, which hindered gas diffusion [112]. However, the hindrance effect on the PEG chains had minimal influence on smaller $\mathrm{CO}_{2}$ molecules compared with bigger $\mathrm{N}_{2}$ molecules with $\mathrm{CO}_{2} / \mathrm{N}_{2}$ selectivity of 43.0 . Thus, this led to separation performance beyond the Robeson upper bound compared with the respective PEG and PSF single polymeric membranes [112].

\section{Polyethylene glycol (PEG)}

Polyethylene glycol (PEG) is a rubbery polymer used in large quantities in the pharmaceutical, cosmetics, and food industries due to its physiological acceptance [113]. PEG has a strong affinity towards $\mathrm{CO}_{2}$ molecules due to its polar ether chain flexibility (Fig. 10) in the polymer [4]. This flexibility allows PEG to easily dissolve acidic gases, which results in higher $\mathrm{CO}_{2}$ permeability [114]. For this reason, PEG is a popular choice as an additive or co-polymer in a polymer blend to improve the properties of the base polymers [106, 115]. Table 3 and Fig. 11 summarise the previous results found in the literature for the PEG blend membranes compared to its pure base membrane. According to Car et al. [116], blending PEG and Pebax ${ }^{\circledR}$ with a 50/50 weight ratio led to a $100 \%$ rise in $\mathrm{CO}_{2}$ permeance and a slight increase in $\mathrm{CO}_{2} / \mathrm{N}_{2}$ selectivity from 75 to 85 at 1 bar and $283{ }^{\circ} \mathrm{K}$, respectively [116]. Other literature also reported similar trends in $\mathrm{CO}_{2}$ permeability and $\mathrm{CO}_{2} / \mathrm{N}_{2}$ selectivity, as shown in Table 3 and Fig. 11.

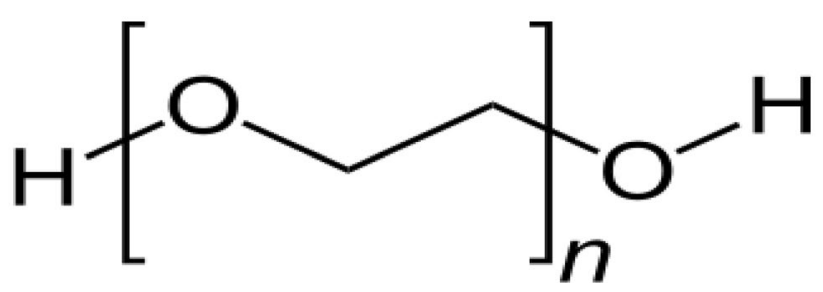

Fig. 10 Structural Formula of PEG [4] 
Table 3 Summary of Results for PEG Blend Membranes

\begin{tabular}{|c|c|c|c|c|c|c|c|c|}
\hline Polymer Blend & $\mathrm{T}\left({ }^{\circ} \mathrm{C}\right)$ & $\mathrm{P}$ (bar) & Gas Mixture (A/B) & $\begin{array}{l}\text { Selectivity of Base } \\
\text { Polymer }\left(\alpha_{A / B_{\text {Base }}}\right)\end{array}$ & $\begin{array}{l}\text { Permeance of } \\
\text { Base Polymer } \\
\left(P_{A_{\text {Base }}}\right)\end{array}$ & $\begin{array}{l}\text { Selectivity of } \\
\text { Blend Polymer } \\
\left(\alpha_{A / B}\right)\end{array}$ & $\begin{array}{l}\text { Permeance of } \\
\text { Blend Polymer } \\
\left(P_{A}\right)\end{array}$ & Ref \\
\hline Pebax $® / P E G-200$ & 10 & 1 & $\mathrm{CO}_{2} / \mathrm{N}_{2}$ & 75 & $50^{\mathrm{a}}$ & 85 & $122^{\mathrm{a}}$ & [116] \\
\hline PSF/PEG-10000 & 30 & 10 & $\mathrm{CO}_{2} / \mathrm{N}_{2}$ & 13.79 & $5.613^{\mathrm{b}}$ & 26.67 & $6.24^{\mathrm{b}}$ & [121] \\
\hline PC/PEG-300 & 25 & 3 & $\mathrm{CO}_{2} / \mathrm{CH}_{4}$ & 26.6 & $5.66^{\mathrm{b}}$ & 40.9 & $4.46^{\mathrm{b}}$ & [122] \\
\hline PES/PEG-10000 & 30 & 10 & $\mathrm{CO}_{2} / \mathrm{N}_{2}$ & 25.9 & $4.2^{\mathrm{b}}$ & 40.79 & $5.26^{\mathrm{b}}$ & [123] \\
\hline PPG/PEG-2000 & 25 & 4 & $\mathrm{CO}_{2} / \mathrm{H}_{2}$ & 140.1 & $3.5^{\mathrm{b}}$ & 68.3 & $4.9^{\mathrm{b}}$ & [124] \\
\hline PPE/PEG-400 & 20 & 6 & $\mathrm{CO}_{2} / \mathrm{N}_{2}$ & 13.3 & $6.1^{\mathrm{a}}$ & 10.6 & $24.7^{\mathrm{a}}$ & [125] \\
\hline CA/PEG-20000 & 35 & 0.03 & $\mathrm{CO}_{2} / \mathrm{N}_{2}$ & 25.8 & $5.96^{\mathrm{b}}$ & 36.2 & $7.49^{\mathrm{b}}$ & [126] \\
\hline
\end{tabular}

$P S F$ polysulfone, $P P E$ poly(2,6-dimethyl-1,4-phenylene oxide), $C A$ cellulose-acetate $P C$ Polycarbonate, $P P G$ Poly(propylene) glycol, $P e b a x \circledR$ polyamide-bethylene oxide

${ }^{\mathrm{a}}$ Gas Permeance Unit (GPU)

${ }^{\mathrm{b}}$ Barrer

Moreover, the addition of PEG has two different influences on the morphology depending on its molecular weight [117]. PEG with low molecular weight is generally in the liquid phase, which tends to act as a pore-forming agent, increasing the number of pores formed and the pore sizes. Meanwhile, PEG with high molecular weight tends to be in the solid phase and has the opposite effect i.e., reduced pore formation and decreased pore size [118]. Therefore, PEG with low molecular weight is generally preferred for gas separation as an increase in pore size and pore density enhances gas permeance but sacrifices selectivity due to upper-bound trade-off [119]. Furthermore, permeation of gases through a PEG membrane may be obstructed due to its high crystalline nature, which can reach up to 71 vol\%. Hence, crystallisation should be inhibited through blending with glassy polymers to increase permeability [120].

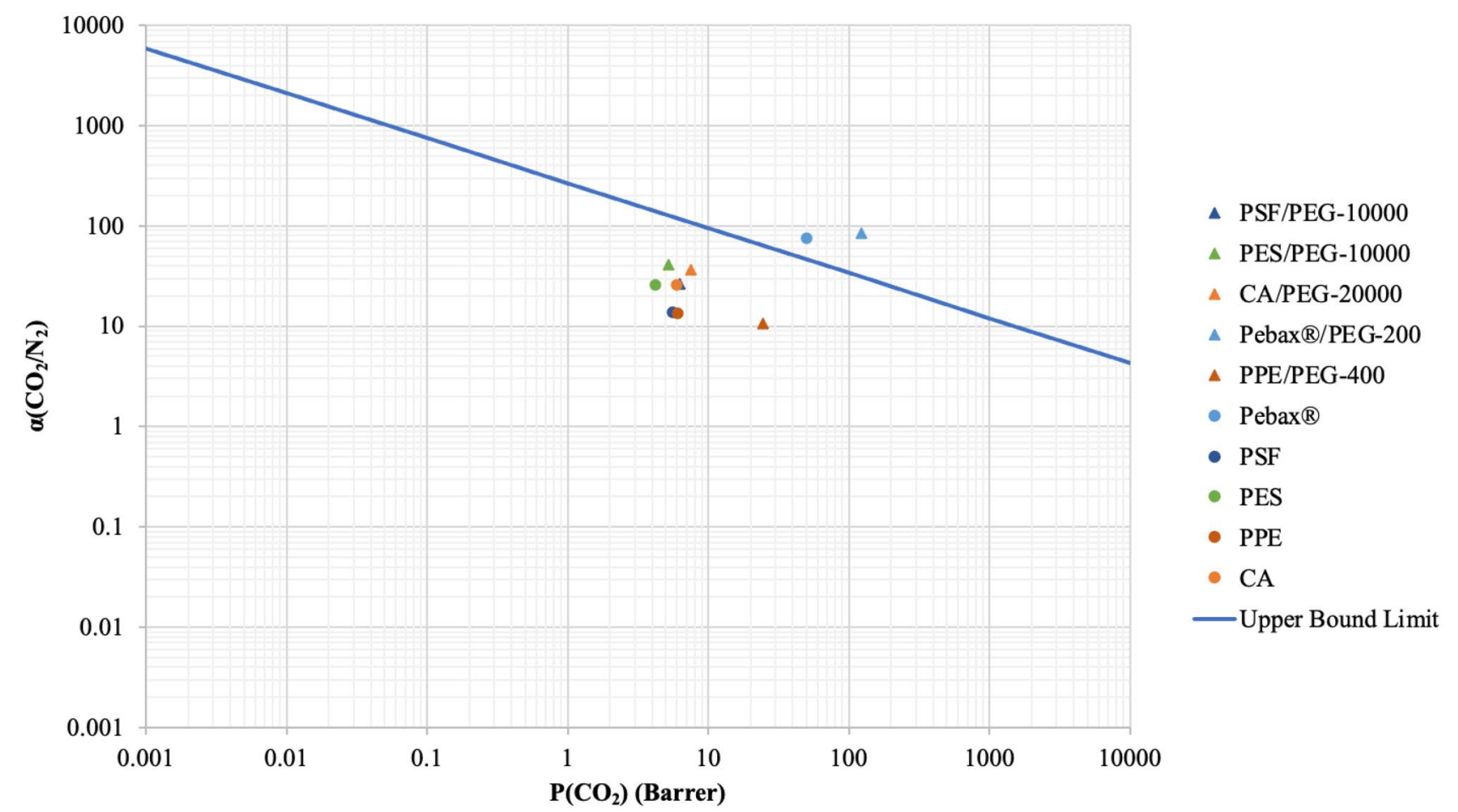

Fig. 11 Gas Separation Performance of PEG Blend Membranes on $\mathrm{CO}_{2} / \mathrm{N}_{2}$ Robeson's Plot 


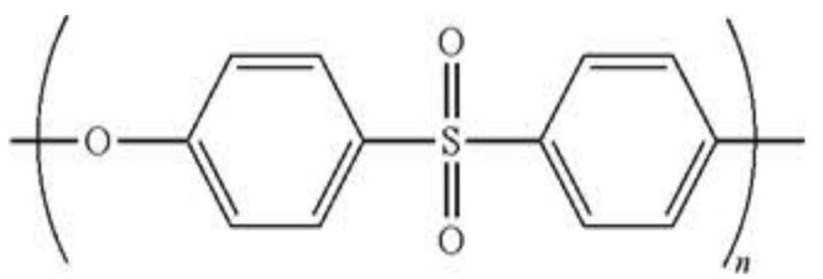

Fig. 12 Structural Formula of PES [82]

\section{Polyethersulfone (PES)}

Polyethersulfone (PES) is a phenyl-based polymer with a glassy structure widely utilised for various membrane applications due to its high thermal resistance, stability, operability, low cost, and gas separation properties [127]. The most popular property of the PES membrane is its high-temperature properties. It can operate continuously at temperatures as high as $200{ }^{\circ} \mathrm{C}$ without causing structural changes or deterioration [82]. This property makes PES suitable for the separation of hot flue gases $[128,129]$. Also, PES can attract $\mathrm{CO}_{2}$ selectively as it possesses an ether-oxygen unit (Fig. 12) that provides a binding mode for $\mathrm{CO}_{2}$ [130]. As PES has a regular and a polar backbone, its polymeric chain is more rigid than rubbery polymers such as PEG [127]. Table 4 and Fig. 13 summarise the performance of PES blend membranes up to date [123, 130-135]. Generally, PES blend membranes have higher selectivity towards $\mathrm{CO}_{2} / \mathrm{N}_{2}$ pairs compared to other gas mixtures such as $\mathrm{CO}_{2} /$ methane $\left(\mathrm{CH}_{4}\right)$ or $\mathrm{O}_{2} / \mathrm{N}_{2}$ [136]. This is due to its ability to condense $\mathrm{CO}_{2}$ and $\mathrm{CH}_{4}$ without allowing $\mathrm{O}_{2}$ and $\mathrm{N}_{2}$ to permeate [130]. Moreover, PES has rapid ageing properties, which could impede gas permeation over time [70]. Chung and Khean Teoh [137] found that the $\mathrm{O}_{2}$ gas permeance of their PES membrane exhibited a 79\% decay over a one year period [137]. The decay in permeance flux of a PES membrane is caused by its tendency to release internal residual stress due to polymer chain relaxation. This accelerates the polymer chain packing which leads to a faster decrease in void fractions and gas permeance [138]. Furthermore, enhancement of permeance and ageing properties of PES membranes is possible through the application of modification approaches, such as polymer blending with rubbery polymers like PEG to decrease polymer chain relaxation $[130,139]$.

\section{N-methyl-2-pyrrolidone (NMP)}

N-Methyl-2-Pyrrolidone (NMP) is an aprotic organic solvent consisting of a 5-membered lactam that is strongly attracted to water, as illustrated in Fig. 14. The solvent is highly polar with a high boiling point $\left(202{ }^{\circ} \mathrm{C}\right)$, low melting point $\left(-23^{\circ} \mathrm{C}\right)$, low volatility, and low viscosity with a mild amine odour [140]. Additionally, NMP is non-toxic and able to withstand high temperatures. These characteristics enabled NMP to become a very useful solvent for a number of chemical reactions where a non-reactive medium is needed [141]. NMP is used in large number of engineering applications, such as material manufacturing, coatings, farm products, telecommunications, paint stripping and washing, among many others. Mubashir et al. [142] stated that the synthesis of CA membranes using the NMP solvent resulted in a higher excess free volume and gas permeation performance [142]. Their research also found that the $\mathrm{CO}_{2}$ permeance increased with higher NMP concentrations in the casting solution. Askari and Chung [143] reported that polyimide (PI) membrane fabricated using the NMP solvent led to a $157 \%$ rise in $\mathrm{CO}_{2} / \mathrm{CH}_{4}$ ideal selectivity compared to the one fabricated using the dichloromethane (DCM) solvent [143, 144]. These results were mainly caused by the enhancement of the hydrogen bonding in the hydroxide $\left(\mathrm{OH}^{-}\right)$segments of the polymers by NMP, which reduces the formation of macrovoids $[142,145]$. Further comparisons of membrane performances for the same gas pairs using NMP solvents and other solvents in previous literature are presented in Table 5
Table 4 Summary of Results for PES Blend Membranes

\begin{tabular}{llllllr}
\hline Polymer Blend & $\mathrm{T}\left({ }^{\circ} \mathrm{C}\right)$ & $\mathrm{P}$ (bar) & Gas Mixture (A/B) & $\begin{array}{l}\text { Selectivity of } \\
\text { Blend Polymer } \\
\left(\alpha_{A / B}\right)\end{array}$ & $\begin{array}{l}\text { Permeance of } \\
\text { Blend Polymer } \\
\left(P_{A}\right)\end{array}$ & Ref \\
\hline PES/PI & 35 & 4 & $\mathrm{CO}_{2} / \mathrm{N}_{2}$ & 40.5 & $37.5^{\mathrm{a}}$ & {$[131]$} \\
PES/PEG-10000 & 30 & 10 & $\mathrm{CO}_{2} / \mathrm{N}_{2}$ & 40.79 & $5.26^{\mathrm{b}}$ & {$[123]$} \\
PES/PSF & 25 & 2 & $\mathrm{CO}_{2} / \mathrm{CH}_{4}$ & 4.0 & $16.0^{\mathrm{a}}$ & {$[132]$} \\
PES/ETPU & 25 & 10 & $\mathrm{CO}_{2} / \mathrm{CH}_{4}$ & 3.37 & $2.26^{\mathrm{a}}$ & {$[133]$} \\
PES/PAI & 25 & 15 & $\mathrm{O}_{2} / \mathrm{N}_{2}$ & 6.93 & $1.43^{\mathrm{a}}$ & {$[134]$} \\
PES/PDMS & 25 & 3.5 & $\mathrm{CO}_{2} / \mathrm{N}_{2}$ & 5.56 & $52^{\mathrm{a}}$ & {$[130]$} \\
PES/PVAc & 25 & 15 & $\mathrm{CO}_{2} / \mathrm{CH}_{4}$ & 1.57 & $5.78^{\mathrm{a}}$ & {$[135]$} \\
\hline
\end{tabular}

PES Polyethersulfone, PI Polyimide, PSF Polysulfone, ETPU Polyeterurethane, PAI Poly(amide-imide), $P D M S$ polydimethylsiloxane, $P V A c$ Polyvinyl acetate

${ }^{\mathrm{a}}$ Gas Permeance Unit (GPU)

${ }^{\mathrm{b}}$ Barrer 


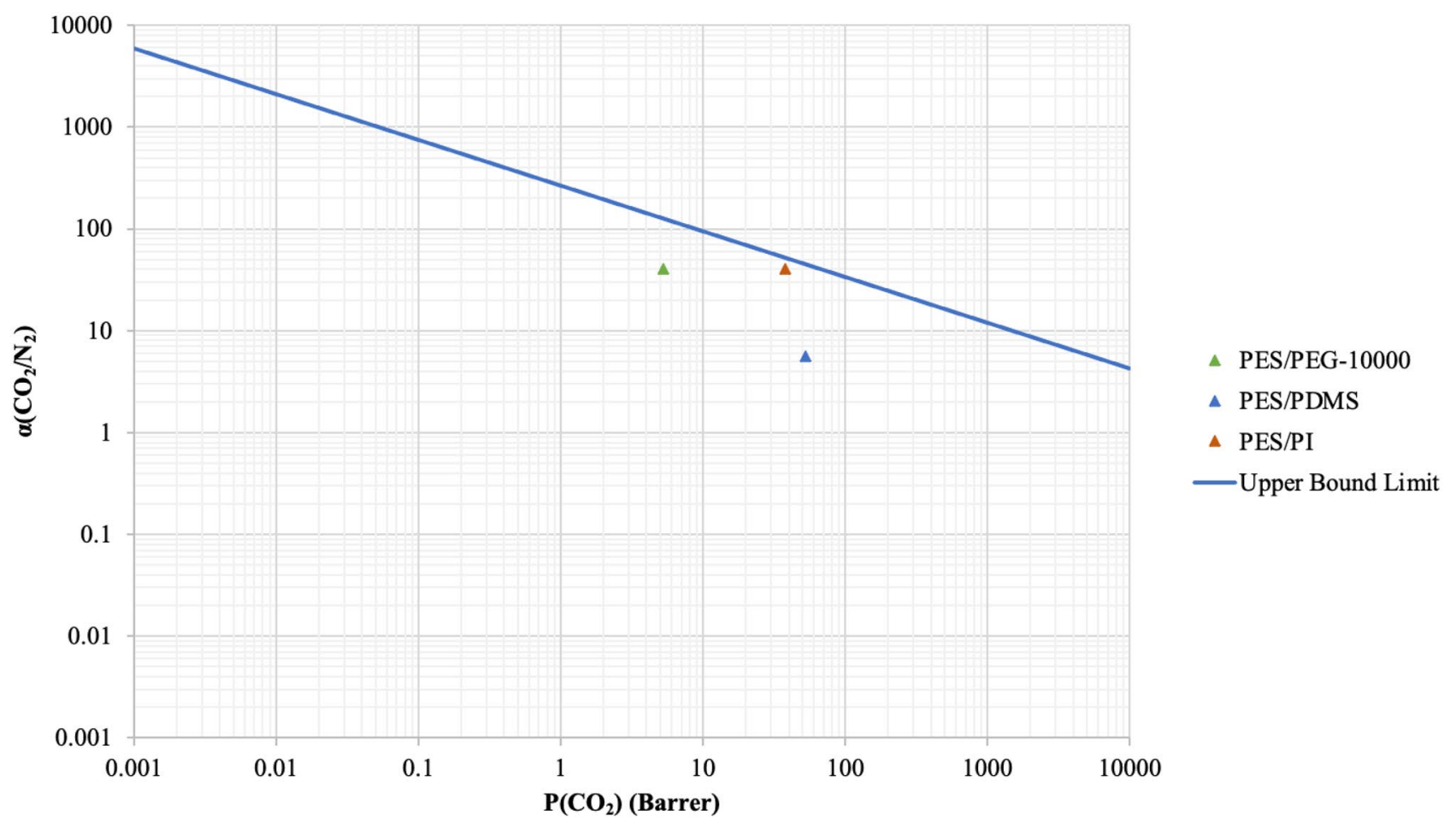

Fig. 13 Gas Separation Performance of PES Blend Membranes on $\mathrm{CO}_{2} / \mathrm{N}_{2}$ Robeson's Plot

and Fig. 15. Additionally, the use of NMP solvent during the membrane synthesis results in a longer solvent evaporation process, leading to a thicker membrane which enhances $\mathrm{CO}_{2}$ permeance. In fact, the longer evaporation time allows the polymer chains to be more rigid, improving the permeation of gases across the synthesized membrane [146].

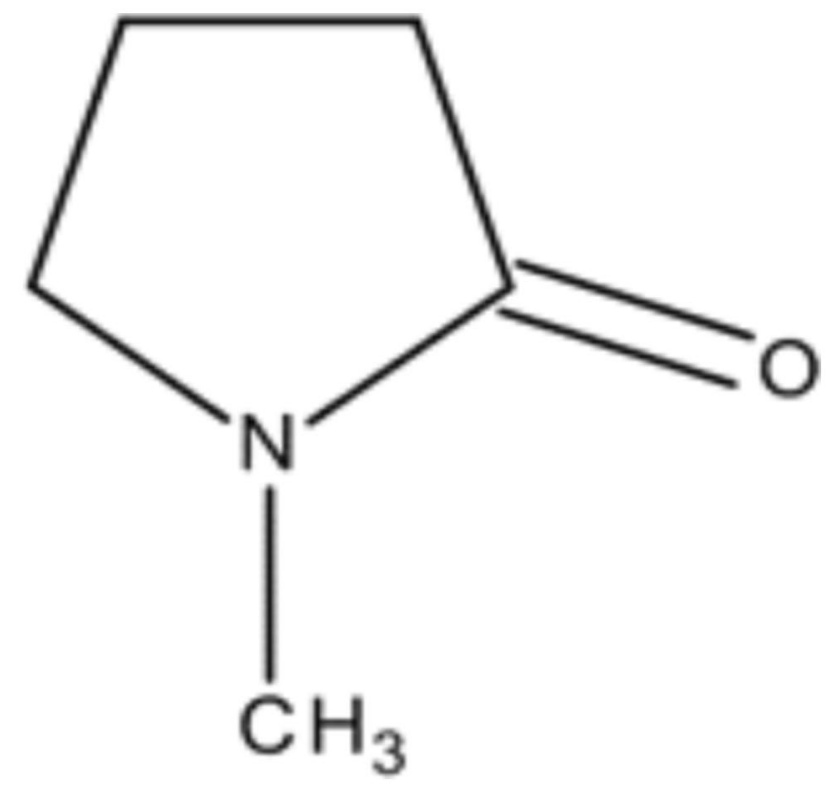

\section{Dimethylformamide (DMF)}

Dimethylformamide (DMF) is a transparent liquid that has been widely applied as a solvent, an additive, or an intermediate in the industry due to its strong miscibility with water and most common organic compounds. The structure of DMF is presented in Fig. 16 [152].

Since DMF is strongly polar, its application as a solvent for polar polymers with strong intermolecular forces can facilitate for hydrogen bonding [153]. DMF has a lower density and viscosity compared to water, along with a high $\mathrm{CO}_{2}$ solubility [154]. According to Karamouz et al. [155], the use of DMF for the synthesis of PEBAX-1074 membranes led to a faster phase-inversion process and higher $\mathrm{CO}_{2}$ permeance (233\%) than the one fabricated using NMP [155]. The phase inversion process was affected by the low thermal resistance of DMF compared to NMP, which was caused by its lower boiling point (Table 6), decreasing the time required for phase-inversion [146, 156]. Ahmad et al. [152] have also shown that the PES-DMF membrane obtained a much higher $\mathrm{CO}_{2}$ permeance (45.7 barrer) when compared to PES-NMP (1.91 barrer) [152]. This trend is consistent in other literature, as shown in Table 7 and Fig. 17. Therefore, it can be established that the use of DMF could result in a permeable membrane with higher selectivity [157].

Fig. 14 Structural Formula of NMP [141] 
Table 5 Comparison of Polymeric Membranes with NMP and Other Solvents

\begin{tabular}{llllllll}
\hline Polymer Blend & $\mathrm{T}\left({ }^{\circ} \mathrm{C}\right)$ & $\mathrm{P}($ bar $)$ & Solvents & Gas Mixture $(\mathrm{A} / \mathrm{B})$ & $\begin{array}{l}\text { Selectivity of } \\
\text { Blend Polymer } \\
\left(\alpha_{A / B}\right)\end{array}$ & $\begin{array}{l}\text { Permeance of } \\
\text { Blend Polymer } \\
\left(P_{A}\right)\end{array}$ & Ref \\
\hline PI & 35 & 10 & $\mathrm{NMP}$ & $\mathrm{CO}_{2} / \mathrm{CH}_{4}$ & 11.68 & $256^{\mathrm{b}}$ & {$[143]$} \\
& 30 & 10 & $\mathrm{DCM}$ & $\mathrm{CO}_{2} / \mathrm{CH}_{4}$ & 4.53 & $283.57^{\mathrm{b}}$ & {$[144]$} \\
PEI & 25 & 1 & $\mathrm{NMP}$ & $\mathrm{CO}_{2} / \mathrm{N}_{2}$ & 1.74 & $10.365^{\mathrm{b}}$ & {$[147]$} \\
& 25 & 3 & $\mathrm{DMF}$ & $\mathrm{CO}_{2} / \mathrm{N}_{2}$ & 1.09 & $10000^{\mathrm{a}}$ & {$[148]$} \\
PES & 25 & 2 & $\mathrm{NMP}$ & $\mathrm{CO}_{2} / \mathrm{N}_{2}$ & 14.9 & $43.2^{\mathrm{a}}$ & {$[149]$} \\
& 30 & 10 & $\mathrm{DMF}$ & $\mathrm{CO}_{2} / \mathrm{N}_{2}$ & 12.39 & $61.6^{\mathrm{a}}$ & {$[150]$} \\
$\mathrm{CA}$ & 25 & 3 & $\mathrm{NMP}$ & $\mathrm{CO}_{2} / \mathrm{CH}_{4}$ & 10.71 & $15.56^{\mathrm{b}}$ & {$[142]$} \\
& 25 & 2 & THF & $\mathrm{CO}_{2} / \mathrm{CH}_{4}$ & 4.15 & $1.08^{\mathrm{b}}$ & {$[151]$} \\
\hline
\end{tabular}

PI Polyimide, PEI Polyetherimide, PES Polyethersulfone, CA Cellulose-acetate, NMP N-Methyl-2-Pyrrolidone, $D C M$ Dichloromethane, $D M F$ Dimethylformamide

${ }^{\mathrm{a}}$ Gas Permeance Unit (GPU)

${ }^{\mathrm{b}}$ Barrer

\section{Membrane fabrication}

\section{Phase-inversion techniques}

A top-quality membrane should be able to achieve close to $100 \%$ selectivity. High selectivity is usually associated with low gas permeance due to the trade-off [161]. The fabrication process of the membrane generally has an important role. In order to produce a membrane with decent separation performance, certain parameters need to be carefully considered. Phase inversion is generally used for the synthesis of blend membranes [162]. It is a process that transforms a homogeneous polymer solution from a liquid state to a solid state [163]. This process utilises the miscibility gap in the ternary phase diagram where the polymer/solvent/nonsolvent system is unstable, causing de-mixing to occur through the formation of a polymer-rich phase and a polymer-lean phase [164]. Phase-inversion may be vapourinduced, non-solvent induced or thermally induced [165].

The vapour-induced phase separation (VIPS) method is done by exposing the casted solution with the volatile solvent to a vapour non-solvent (humid air) and letting

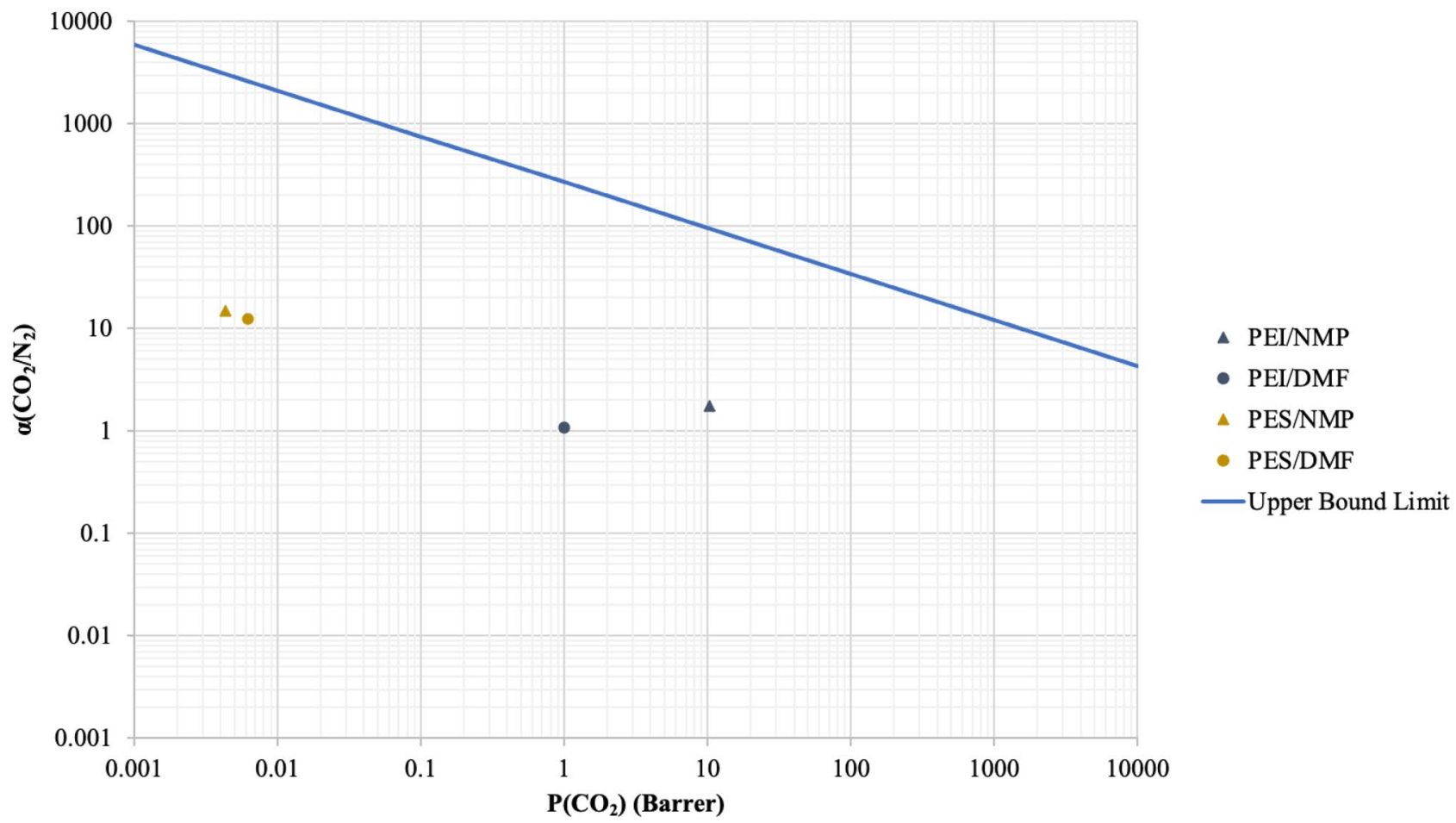

Fig. 15 Gas Separation Performance of Fabricated Polymeric Membranes using NMP and Other Solvents on $\mathrm{CO}_{2} / \mathrm{N}_{2}$ Robeson's Plot 


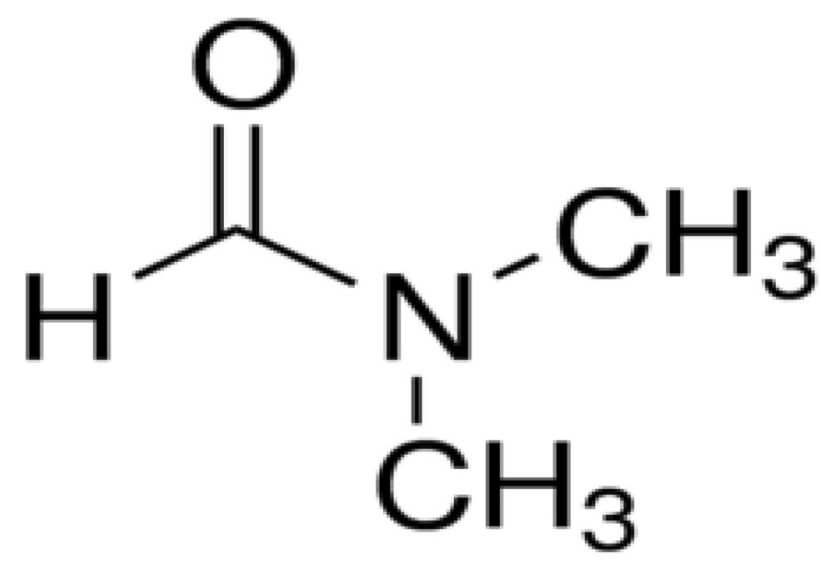

Fig. 16 Structural Formula of DMF [152]

evaporation take place [70]. The non-solvent vapour is absorbed by the polymer solution, triggering the de-mixing process, and eventually forms a membrane. Regarding the non-solvent induced phase separation (NIPS) method, the casted solution is immersed into a non-solvent bath, where solvent/non-solvent interaction occurs [165]. The thermally induced phase separation (TIPS) is widely used due to its simplicity, high reproducibility, low trend to create defeats, high porosity, and the ability to create microstructures with a narrow pore size distribution. Additionally, TIPS can handle polymer polymorphism [166]. In TIPS, a "latent solvent" is utilised for the phase-inversion [164]. A latent solvent is a compound that is only able to dissolve the polymers at high temperatures but not at low temperatures [167]. Therefore, TIPS involves preparing a cast solution through polymer blending with latent solvent at high temperatures and inducing phase transition through a temperature drop [167]. A diagram of the different phase-inversion processes is represented in Fig. 18 [168].

The ternary phase diagram in Fig. 19 can be used to describe the phase inversion process [169]. Each end of the triangle represents the three components of the casting solution, such as polymer, solvent, and nonsolvent, where any point on the triangle is comprised of all the three components.

Phase-inversion starts once the casting solution with a predetermined polymer, solvent, and non-solvent concentration

Table 6 Properties of NMP and DMF [156]

\begin{tabular}{llllll}
\hline Solvent & $\begin{array}{l}\text { Density at } \\
\begin{array}{l}2{ }^{\circ} \mathrm{C}(\mathrm{g} / \\
\left.\mathrm{cm}^{3}\right)\end{array}\end{array}$ & $\begin{array}{l}\text { Viscosity } \\
(\mathrm{mPa} . \mathrm{s})\end{array}$ & $\begin{array}{l}\text { Boiling } \\
\text { Point } \\
\left({ }^{\circ} \mathrm{C}\right)\end{array}$ & $\begin{array}{l}\text { Surface } \\
\text { Tension } \\
(\mathrm{mN} / \mathrm{m})\end{array}$ & $\begin{array}{l}\text { Evapora- } \\
\text { tion time } \\
\text { for } 90 \% \text { of } \\
\text { Solvent }(\mathrm{s})\end{array}$ \\
\hline $\mathrm{DMF}$ & 0.95 & 0.8 & 153 & 36.4 & 2280 \\
$\mathrm{NMP}$ & 1.03 & 1.7 & 202 & 40.7 & 15,400 \\
\hline
\end{tabular}

(Point A) is casted on the casting machine. Then, de-solvation occurs through solvent evaporation and solvent/non-solvent exchange. This process changes the composition of polymer on $\mathrm{ABC}$ to the two-phase area that consists of a solid porous phase and a liquid phase [170]. The first step of de-solvation occurs through solvent evaporation and instant formation of a thin skin layer of solid polymer at the top of the cast film due to the loss of solvent [171].

At point $\mathrm{B}$, a transition takes places from one phase to the two-phase area in which the mixture breaks into a polymerrich phase and a polymer-lean phase [169]. At this moment, solvent/non-solvent exchange process occurs where nonsolvent diffuses into the polymer film through the thin solid layer while solvent diffuses out. This results in a low solvent composition in the solution film which can no longer hold polymer in one phase [172].

Point $\mathrm{C}$ shows the net membrane at which the two-phase region is in equilibrium, where point $\mathrm{S}$ is the solid (polymer rich) phase and point $\mathrm{L}$ is the liquid (polymer-lean) phase. On the line S-L, the position of $\mathrm{C}$ can be used to determine the membrane morphology [173, 174]. The polymer-rich phase becomes solid at point $\mathrm{D}$. At this point, the thin layer that forms during the first evaporation step becomes the top skin layer, governing the selectivity and the flux of the membrane. Meanwhile, the porous structure that forms during the solvent/non-solvent exchange step becomes the porous sub-layer, providing mechanical strength [175]. Hence, an

Table 7 Comparisons of Polymeric Membranes with DMF and Other Solvents

\begin{tabular}{|c|c|c|c|c|c|c|c|}
\hline $\begin{array}{l}\text { Polymer } \\
\text { Blends }\end{array}$ & $\begin{array}{l}\mathrm{T} \\
\left({ }^{\circ} \mathrm{C}\right)\end{array}$ & $\begin{array}{l}\mathrm{P} \\
\text { (bar) }\end{array}$ & Solvents & $\begin{array}{l}\text { Gas } \\
\text { Mixture } \\
(\mathrm{A} / \mathrm{B})\end{array}$ & $\begin{array}{l}\text { Selectiv- } \\
\text { ity of } \\
\text { Blend } \\
\text { Polymer } \\
\left(\alpha_{A / B}\right)\end{array}$ & $\begin{array}{l}\text { Permeance } \\
\text { of Blend } \\
\text { Polymer } \\
\left(P_{A}\right)\end{array}$ & Ref \\
\hline \multirow[t]{2}{*}{ PES } & 25 & 2 & $\mathrm{DMF}$ & $\begin{array}{c}\mathrm{CO}_{2} / \\
\mathrm{CH}_{4}\end{array}$ & 2.56 & $45.7^{\mathrm{b}}$ & [152] \\
\hline & 25 & 2 & NMP & $\begin{array}{c}\mathrm{CO}_{2} / \\
\mathrm{CH}_{4}\end{array}$ & 2.40 & $1.91^{\mathrm{b}}$ & \\
\hline \multirow[t]{2}{*}{$\begin{array}{c}\text { PEBAX- } \\
1074\end{array}$} & 25 & 5 & DMF & $\begin{array}{c}\mathrm{CO}_{2} / \\
\mathrm{CH}_{4}\end{array}$ & 18.9 & $434^{\mathrm{b}}$ & [155] \\
\hline & 25 & 5 & NMP & $\begin{array}{c}\mathrm{CO}_{2} / \\
\mathrm{CH}_{4}\end{array}$ & 16 & $130^{\mathrm{b}}$ & [158] \\
\hline \multirow[t]{2}{*}{ PEI } & 25 & 5 & DMF & $\mathrm{CO}_{2} / \mathrm{N}_{2}$ & 2.0 & $6.0^{\mathrm{a}}$ & [159] \\
\hline & 25 & 5 & GBL & $\mathrm{CO}_{2} / \mathrm{N}_{2}$ & 0.5 & $0.2^{\mathrm{a}}$ & \\
\hline \multirow[t]{2}{*}{ PI } & 25 & 3 & DMF & $\mathrm{CO}_{2} / \mathrm{N}_{2}$ & 16.95 & $187^{\mathrm{b}}$ & [160] \\
\hline & 25 & 3 & DCM & $\mathrm{CO}_{2} / \mathrm{N}_{2}$ & 15.79 & $89.0^{\mathrm{b}}$ & \\
\hline
\end{tabular}

PI Polyimide, PEI Polyetherimide, PES Polyethersulfone, NMP N-Methyl-2-Pyrrolidone, $D C M$ Dichloromethane, $D M F$ Dimethylformamide, $G B L \gamma$-butyrolactone, DCM Dichloromethane

${ }^{\mathrm{a}}$ Gas Permeance Unit (GPU)

${ }^{\mathrm{b}}$ Barrer 


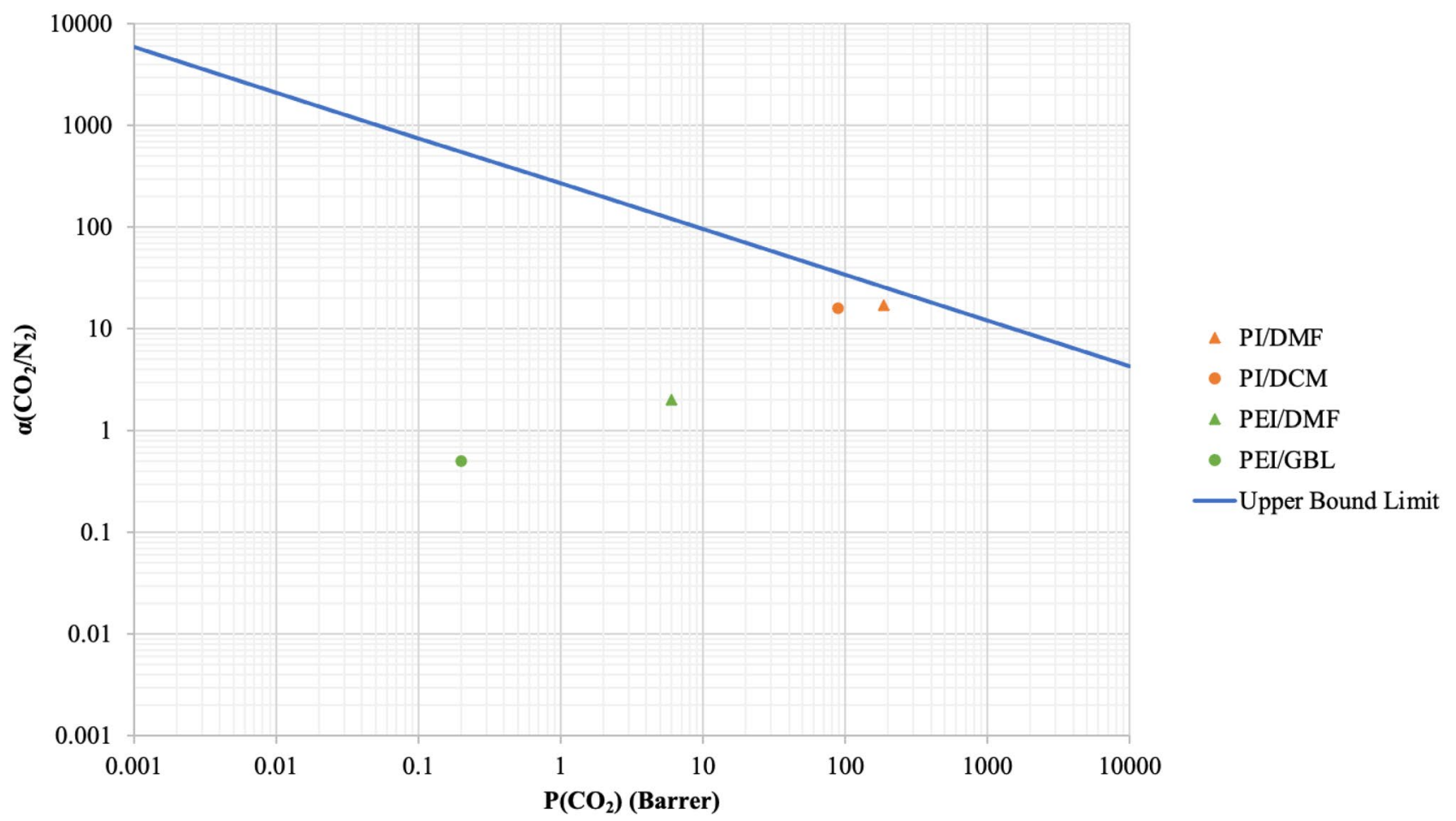

Fig. 17 Gas Separation Performance of Fabricated Polymeric Membranes using DMF and Other Solvents on $\mathrm{CO}_{2} / \mathrm{N}_{2}$ Robeson's Plot

integrally skinned asymmetric membrane is obtained from the phase-inversion process.

It should also be noted that the morphology of the final membrane is developed in the phase-inversion process is highly dependent on the time taken for it to take place [176]. The size of the polymer-lean phase dispersed in the polymerrich phase depends on the time taken to move from $\mathrm{B}$ to $\mathrm{C}$ [169]. Shorter time leads to a denser polymer gel formed at $\mathrm{C}$ instead of a porous structure due to the smaller size of the polymer-lean phase. Furthermore, the time taken from $\mathrm{B}$ to $\mathrm{C}$ depends on the distance from the cast polymer film/ non-solvent interface where the initial thin dense upper layer is formed [170]. The speed of solvent/nonsolvent exchange is slowed down by the formation of the dense layer and a sub-layer with sponge-like pores is formed under the dense layer. However, a more permeable finger-like sub-layer can

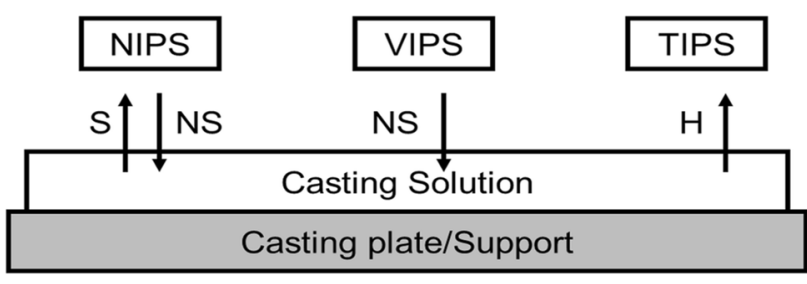

Fig. 18 Schematic of the four main phase inversion processes (S: Solvent, NS: Nonsolvent, H: Heat) [168] also be formed when the influx of non-solvent is much lower than the outflux of solvents, which enhances the growth of the polymer-lean phase [177].

\section{Polymer blend}

The synthesis of membranes through blending of polymers has grown rapidly, regardless of the miscibility of the polymer blend [178]. Polymer blending is remarkable because it provides a practical method to combine the benefits of each polymer into a single new material. Further, a continuous range of performance is predicted by changing the composition of the blend. This method offers an easy and cost-effective combination of polymers with different separation and physicochemical properties to obtain the desired superior properties which could not be achieved by each polymers individually [106, 179]. Interestingly, blends that consist of glassy and rubbery polymers have proven to yield membranes with better $\mathrm{CO}_{2}$ separation properties [180]. This is due to the distinct methods of gas separation provided by each polymer type. Rubbery polymers carry out gas separation based on condensability. Gas separation in glassy polymers is dependent on the molecular sizes of the gas particles [130]. Furthermore, the addition of rubbery PEG into glassy PES can increase excess free volume and add flexibility to the PES chain. This increases the permeance of PES by preventing polymer relaxation $[139,181]$. 
Fig. 19 Schematic diagram of the ternary plot describing the phase-inversion process [169]

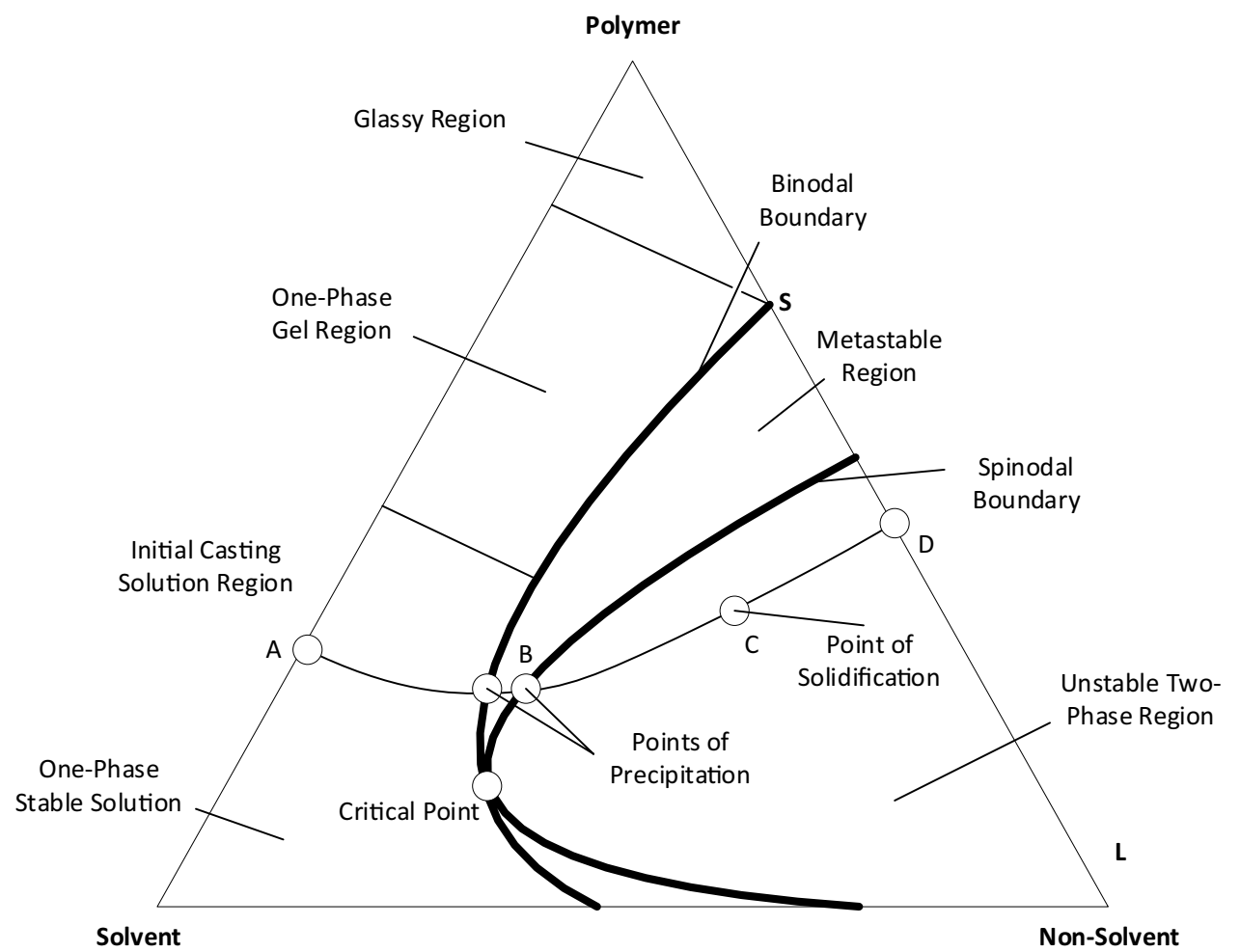

Akbarian et al. [123] have reported that blending PEG and PES resulted in a $26 \%$ increase in $\mathrm{CO}_{2}$ permeance and a $64 \%$ increase in perm-selectivity for $\mathrm{CO}_{2} / \mathrm{N}_{2}$ separation [123].

Additionally, the polymer concentration in a casting solution is defined as the most important parameter for the enhancement of membrane properties through blend membranes [182]. Generally, an increase of polymer content in a dope solution should form a denser skin layer which is more selective [183]. Moreover, an asymmetric membrane with a very thin surface layer yields a membrane with a high gas permeance. However, high gas permeance in a polymeric membrane leads to a trade-off in selectivity and vice versa. Furthermore, higher PEG content in the casting solution results in an increase of rubbery segments that leads to a higher dominance of gas separation through adsorption [184]. Further, the pore-forming and pore-reducing effects of PEG of different molecular weights must also be considered due to the relationship between $\mathrm{CO}_{2} / \mathrm{N}_{2}$ selectivity and $\mathrm{CO}_{2}$ permeance [118, 185]. PEG with low molecular weights results in higher gas permeation with the cost of selectivity, while the PEG with high molecular weights results in the opposite effect [186]. In order to synthesise a membrane with optimum selectivity and permeability, it is necessary to decide the optimum concentration of the polymer in the casting solution.

\section{Solvent blend}

Apart from polymers, the amounts of solvents chosen for the phase-inversion process is also an important parameter for achieving the desired separation performance of the final membrane. Ahmad et al. [152] and Mubashir et al. [142] have indicated that NMP and DMF are the most suitable solvents for separation of $\mathrm{CO}_{2}$ from $\mathrm{N}_{2}$ due to their high $\mathrm{CO}_{2} / \mathrm{N}_{2}$ selectivity and $\mathrm{CO}_{2}$ solubility, respectively. However, NMP has better thermal resistance when compared to DMF, which results in a longer solvent evaporation time $[142,152]$. Jami' an et al. [187] reported that solvent evaporation time increases with higher concentration of NMP, leading to a decreased surface porosity and a thicker final membrane that promotes $\mathrm{CO}_{2} / \mathrm{CH}_{4}$ selectivity [187]. On the contrary, increase of DMF solvent concentration leads to a faster phase-inversion process due to its lower boiling point [155]. Isanejad et al. [146] stated that $\mathrm{CO}_{2}$ permeance and $\mathrm{CO}_{2} / \mathrm{N}_{2}$ selectivity increases with higher DMF concentration having minimal trade-off compared to NMP due to the higher formation of macrovoids [146]. In this regard, choosing one solvent above the other results in a trade-off between permeance and perm-selectivity. This trade-off decreases the overall separation efficiency. According to Fashandi and Karimi [188], mixing of NMP and DMF solvents may improve the fabrication of the PES membrane [188]. They 
reported that adding DMF to PES/NMP mixture, causes the VIPS process to proceed faster, promoting formation of long thin fibres, which are typically the site for adsorption. Based on the properties of NMP and DMF, the idea of mixing the two solvents to obtain the best properties is the logical option. Additionally, the solvent concentrations should be carefully considered as different solvent concentration affects the viscosity of the casting solution, influencing the polymer-solvent interactions during the phase-inversion process [189].

\section{Casting thickness}

Casting thickness can be considered as one the most crucial factors that should be studied for the synthesis of an effective membrane [190]. This is mainly caused by the effect of casting thickness on the membrane structure, which alters its performance and properties [191]. Vogrin et al. [192] studied the influence of cast solution thickness on the structure of cellulose acetate (CA)//acetone/ $\mathrm{H}_{2} \mathrm{O}$ system [192]. Their work revealed that a structural transformation (finger-like to sponge-like structure) occurred with respect to the membrane thickness of $\mathrm{CA} /$ acetone $/ \mathrm{H}_{2} \mathrm{O}$ system i.e., between 300 and $500 \mu \mathrm{m}$. This indicated that membrane structures may vary depending on casting thickness. Meanwhile, Ahmad et al. [147] studied the performance of the PEI membranes of different thicknesses and found that a higher casting thickness of $300 \mu \mathrm{m}$ led to an increase in $\mathrm{CO}_{2} / \mathrm{N}_{2}$ ideal selectivity from 1.74 to 2.56 , as well as a major drop in $\mathrm{CO}_{2}$ permeance from 10.37 to 2.59 barrer [147]. The $\mathrm{CO}_{2}$ permeance decreased significantly due to the formation of a thicker selective skin layer and larger finger-like macrovoids leading
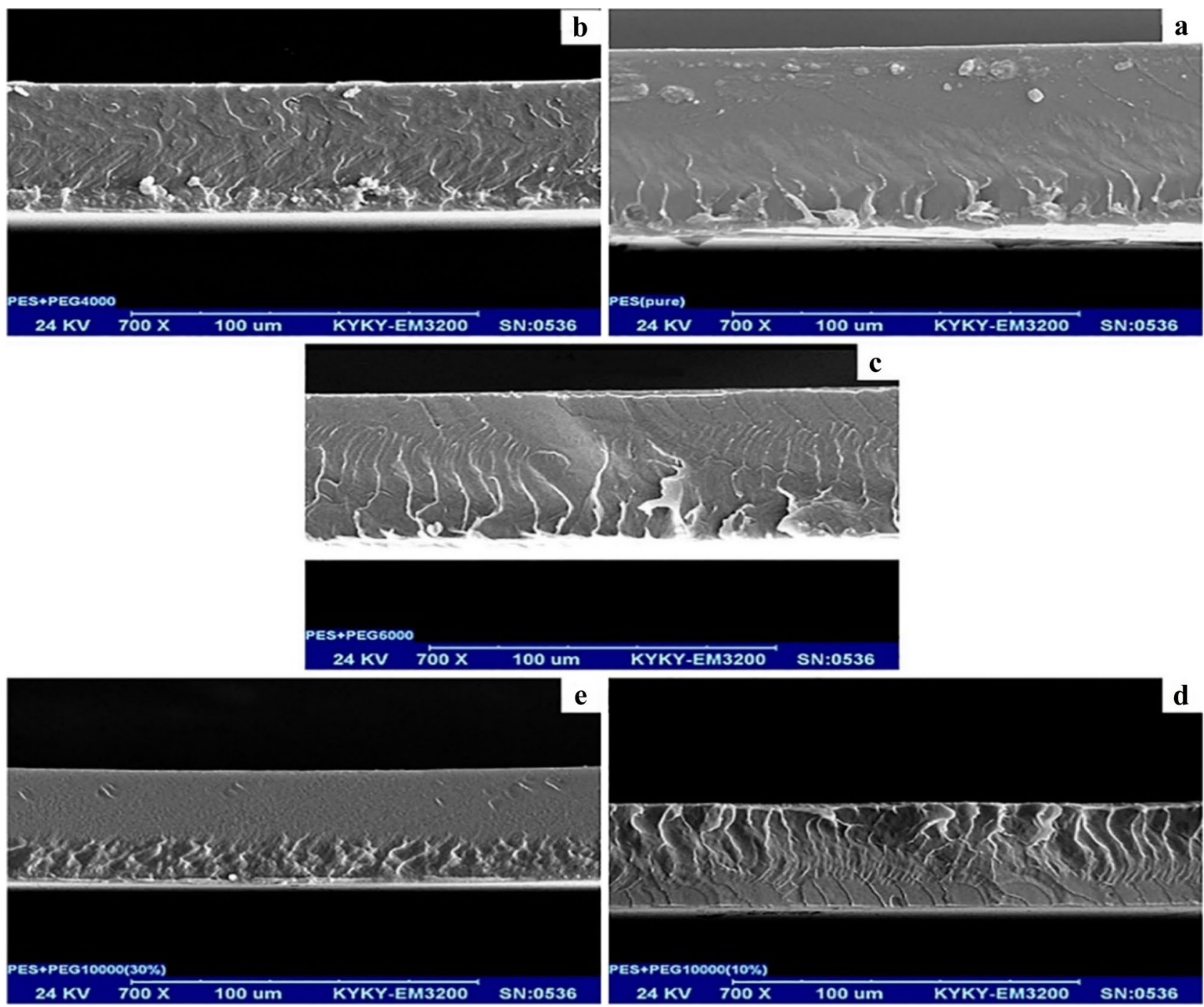

Fig. 20 Cross-sectional SEM micrographs of the a pure PES, b PES-10\% PEG4000, c PES-10\% PEG6000, d PES-10\% PEG10000, and e PES$30 \%$ PEG10000 $(700 \times)[123]$ 
to a denser membrane which hindered permeation of $\mathrm{CO}_{2}$. Sugu and Jawad [193] studied the effects of casting thickness on CA membranes and found a similar trend in their research where $\mathrm{CO}_{2}$ permeance decreases with increase in casting thickness [193, 194]. However, they also discovered that a drop in both permeance and selectivity of a CA membrane occurred when the casting thickness was above $300 \mu \mathrm{m}$. As a result, macrovoids started to show major defects due to high non-solvent influx into the polymer matrix in thicker membranes, forming a more porous structure [195]. Their research also stated that the optimum casting thickness for their CA membrane was $300 \mu \mathrm{m}$, achieving the optimum $\mathrm{CO}_{2} / \mathrm{N}_{2}$ ideal selectivity of 3.01 and $\mathrm{CO}_{2}$ permeability of 401.17 GPU. Other than gas separation properties, thermal strength and mechanical properties are also affected by casting thickness. According to Rahman et al. [196], the thermal resistance of PolyActive membrane increases with casting thickness as the melting point of the thinner PolyActive membrane of $0.2 \mu \mathrm{m}$ was $10{ }^{\circ} \mathrm{C}$ lower than that of its thicker $8 \mu \mathrm{m}$ counterpart [196]. Therefore, casting thickness should be thoroughly studied as it affects gas separation performance, thermal properties, and mechanical characteristics of the membrane [147].

\section{Structure of PEG/PES membranes}

Akbarian et al. [123] examined the influence of different PEG molecular weights and concentrations on gas separation properties, morphologies, and mechanical strengths of PES/ PEG blend membranes [123]. These blend membranes were fabricated using TIPS method at a temperature of $60^{\circ} \mathrm{C}$. Figure 20 presents the cross-sectional scanning electron microscope (SEM) micrographs of the PES/PEG membranes with variation in PEG molecular weights. Figure 20 also shows that no major changes were found in the morphologies of the membranes due to the rise in PEG or molecular weights. The presence of smooth and void-free surfaces also verified the suitability of the blend, as only one phase was visible in the blend membranes [109]. This resulted from the homogeneity of PES/PEG blend in the casting solution, which caused even distribution of the two polymers across the membrane [107]. The lack of pores on the surface of the membranes established that the membranes were dense and compact [123]. The formation of a dense structure is more desirable as gas-separation requires a dense layer to build up pressure and segregate small gas molecules [197].

\section{Conclusion}

Due to the high energy cost of conventional $\mathrm{CO}_{2}$ separation processes, an alternative technology is highly required in order to further enhance the application of CCS. To meet the growing demand for $\mathrm{CO}_{2}$ separation, the membrane separation technology based on high-performance polymer membranes is promising and attractive. Polymeric membranes are the preferred choice for commercial applications due to simpler method of fabrication and a much lower cost compared to inorganic membranes or MMM. However, the gas separation performance of polymeric membranes is limited due to plasticisation issues and upper-bound trade-off between selectivity and permeability. Recent studies have found that trade-off between selectivity and permeability can be effectively minimised through the blending of glassy and rubbery polymers. The development of PES/PEG blend membranes has led to a large improvement in $\mathrm{CO}_{2} / \mathrm{N}_{2}$ selectivity which resulted in an overall gas separation performance that is closer to Robeson's upper-bound. The review provides background on CCS, $\mathrm{CO}_{2}$ separation, and membrane technology. The recent developments in blend membrane materials have been discussed focusing on PEG, PES, DMF, and NMP. Additionally, the effect of parameters concerning the fabrication process, such as polymer concentration, solvent concentration, and casting thickness were discussed in order to further enhance the properties of gas separation for PES/PEG blend membranes.

\section{Future prospect}

Despite the ability to overcome the upper bound trade-off, PES/PEG blend membranes can still be developed further in order to lower $\mathrm{CO}_{2}$ capture costs compared to the US DOE targets. Up to date, studies on PEG/PES blend membranes have only involved DMF as a solvent. In order to improve $\mathrm{CO}_{2}$ permeation in PEG/PES blend membranes, one promising approach is to fabricate the blend membrane using NMP/DMF solvent mixture. Results from literature have indicated that the involvement of NMP results in a longer solvent evaporation time, which in turn increases the final thickness of the membrane and its $\mathrm{CO}_{2} / \mathrm{N}_{2}$ selectivity. With regards to that, future research on PEG/PES blend membranes should consider exploring the optimum PEG/ PES/NMP:DMF blend concentration as well as its optimum casting thicknesses to yield a polymeric membrane with high permeability and $\mathrm{CO}_{2} / \mathrm{N}_{2}$ selectivity. This could lead to a membrane with properties that sits even closer or beyond the upper-bound in the Robeson's plot and encourage its application in the gas separation industry.

Supplementary Information The online version contains supplementary material available at https://doi.org/10.1007/s10965-021-02500-6.

Acknowledgements There is no financial funding supporting the manuscript.

Funding Open Access funding provided by the Qatar National Library. 
Data Availability The authors confirm that no datasets were generated during the current study. Data reviewed in this study were a re-analysis of existing data, which are openly available at locations cited in the reference section.

\section{Declarations}

Competing interest The authors declare that they have no known competing financial interests or personal relationships that could have appeared to influence the work reported in this manuscript.

Open Access This article is licensed under a Creative Commons Attribution 4.0 International License, which permits use, sharing, adaptation, distribution and reproduction in any medium or format, as long as you give appropriate credit to the original author(s) and the source, provide a link to the Creative Commons licence, and indicate if changes were made. The images or other third party material in this article are included in the article's Creative Commons licence, unless indicated otherwise in a credit line to the material. If material is not included in the article's Creative Commons licence and your intended use is not permitted by statutory regulation or exceeds the permitted use, you will need to obtain permission directly from the copyright holder. To view a copy of this licence, visit http://creativecommons.org/licenses/by/4.0/.

\section{References}

1. Ritchie H, Roser M (2020) CO2 and Greenhouse Gas Emissions. Our World Data

2. Morice CP et al (2012) Quantifying uncertainties in global and regional temperature change using an ensemble of observational estimates: The HadCRUT4 data set. J Geophys Res: Atmos 117(D8)

3. Bereiter B et al (2015) Revision of the EPICA Dome C CO2 record from 800 to $600 \mathrm{kyr}$ before present. Geophys Res Lett 42(2):542-549

4. Liu J et al (2016) High-Performance Polymers for Membrane CO2/ N2 Separation. Chemistry - A Euro J, 22(45):15980-15990

5. United States Environmental Protection Agency (2018) Global Greenhouse Gas Emissions Data. [cited 2019 Dec 24] Available from: https://www.epa.gov/ghgemissions/global-greenhouse-gasemissions-data

6. Zakaria $\mathrm{Z}$ et al (2020) A review of progressive advanced polymer nanohybrid membrane in fuel cell application. Int J Energy Res

7. Markewitz P, Bongartz R (2015) Carbon capture technologies. $p$ $13-45$

8. IEA (2019) CO2 Emissions from Fuel Combustion 2019 Edition. [cited 2019 Dec 24]

9. IEA (2019) Global Energy \& CO2 Status Report 2019. cited 2019 [December 24] Available from: https://www.iea.org/reports/ global-energy-and-co2-status-report-2019/emissions\#abstract

10. Venna SR, Carreon MA (2011) Amino-Functionalized SAPO-34 Membranes for $\mathrm{CO} 2 / \mathrm{CH} 4$ and $\mathrm{CO} 2 / \mathrm{N} 2$ Separation. Langmuir 27(6):2888-2894

11. Desideri U, Arcioni L, Tozzi M (2008) Feasibility study for a carbon capture and storage project in northern Italy. Int J Energy Res 32(12):1175-1183

12. Chen B, Pawar RJ (2019) Capacity assessment and co-optimization of $\mathrm{CO} 2$ storage and enhanced oil recovery in residual oil zones. J Petrol Sci Eng 182:106342

13. Theeyattuparampil VV et al (2013) Carbon capture and storage. Int J Energy Sect Manage 7(2):223-242
14. Mason JA et al (2015) Application of a High-Throughput Analyzer in Evaluating Solid Adsorbents for Post-Combustion Carbon Capture via Multicomponent Adsorption of CO2, N2, and H2O. J Am Chem Soc 137(14):4787-4803

15. IEA (2019) Transforming Industries Through CCUS. [cited 2019 Dec 24] Available from: https://webstore.iea.org/download/ direct $/ 2778$

16. Leung DYC, Caramanna G, Maroto-Valer MM (2014) An overview of current status of carbon dioxide capture and storage technologies. Renew Sustain Energy Rev 39:426-443

17. Gibbins J, Chalmers H (2008) Carbon capture and storage. Energy Policy 36(12):4317-4322

18. Najafabadi AT (2013) CO2 chemical conversion to useful products: An engineering insight to the latest advances toward sustainability. Int J Energy Res 37(6):485-499

19. Theo WL et al (2016) Review of pre-combustion capture and ionic liquid in carbon capture and storage. Appl Energy 183:1633-1663

20. Scholes CA et al (2010) CO2 capture from pre-combustion processes-Strategies for membrane gas separation. Int J Greenhouse Gas Control 4(5):739-755

21. Jansen D et al (2015) Pre-combustion CO2 capture. Int J Greenhouse Gas Control 40:167-187

22. Nemitallah MA et al (2017) Oxy-fuel combustion technology: current status, applications, and trends. Int J Energy Res 41(12):1670-1708

23. Ahmed $\mathrm{R}$ et al (2020) Recent advances in carbon-based renewable adsorbent for selective carbon dioxide capture and separation-A review. J Clean Prod 242:118409

24. Global CCS (2012) Institute, CO2 capture technologies: PreCombustion Capture

25. Stanger $\mathrm{R}$ et al (2015) Oxyfuel combustion for $\mathrm{CO} 2$ capture in power plants. Int J Greenhouse Gas Control 40:55-125

26. Adu E, Zhang Y, Liu D (2019) Current situation of carbon dioxide capture, storage, and enhanced oil recovery in the oil and gas industry. Can J Chem Eng 97(5):1048-1076

27. Olajire AA (2010) CO2 capture and separation technologies for end-of-pipe applications - A review. Energy 35(6):2610-2628

28. Perrin $\mathrm{N}$ et al (2015) Oxycombustion for coal power plants: Advantages, solutions and projects. Appl Therm Eng 74:75-82

29. Songolzadeh M et al (2014) Carbon Dioxide Separation From Flue Gases: A Technological, Review Emphasizing Reduction in Greenhouse Gas Emissions. Sci World J 2014:828131

30. Sharma M, Parvareh F, Abbas A (2015) Highly integrated postcombustion carbon capture process in a coal-fired power plant with solar repowering. Int J Energy Res 39(12):1623-1635

31. Zhang X et al (2020) Comparative Economic Analysis of Physical, Chemical, and Hybrid Absorption Processes for Carbon Capture. Ind Eng Chem Res 59(5):2005-2012

32. Ahmad AL, Salaudeen YO, Jawad ZA (2019) Polymeric Membrane for Flue Gas Separation and Other Minor Components in Carbon Dioxide Capture. p 39-73

33. Feron P, Hendriks C (2005) CO 2 Capture Process Principles and Costs. Oil \& Gas Science and Technology-revue De L Institut Francais Du Petrole - OIL GAS SCI TECHNOL 60:451-459

34. Pires JCM et al (2011) Recent developments on carbon capture and storage: An overview. Chem Eng Res Des 89(9):1446-1460

35. Hussin F, Aroua MK (2020) Recent trends in the development of adsorption technologies for carbon dioxide capture: A brief literature and patent reviews (2014-2018). J Clean Prod 253:119707

36. Raza A et al. (2019) Significant aspects of carbon capture and storage $-\mathrm{A}$ review.

37. Li JR et al (2011) Carbon dioxide capture-related gas adsorption and separation in metal-organic frameworks. Coord Chem Rev 255(15):1791-1823 
38. Zhao L et al (2010) Multi-stage gas separation membrane processes used in post-combustion capture: Energetic and economic analyses. J Membr Sci 359(1):160-172

39. Florin $\mathrm{N}$ et al (2010) An overview of CO 2 capture technologies. Energy Environ Sci 3:1645-1669

40. Yang $\mathrm{H}$ et al (2008) Progress in carbon dioxide separation and capture: A review. J Environ Sci 20(1):14-27

41. Takamura Y et al (2001) Application of high-pressure swing adsorption process for improvement of $\mathrm{CO} 2$ recovery system from flue gas. Can J Chem Eng 79(5):812-816

42. McKee B (2002) Solutions for 21 st century, Zero emissions technologies for fossil fuels, Technology Status report. IEA WPFF p 1-47

43. Pirngruber GD, Leinekugel-le-Cocq D (2013) Design of a Pressure Swing Adsorption Process for Postcombustion CO2 Capture. Ind Eng Chem Res 52(17):5985-5996

44. Ntiamoah A et al (2016) CO2 Capture by Temperature Swing Adsorption: Use of Hot CO2-Rich Gas for Regeneration. Ind Eng Chem Res 55(3):703-713

45. Tucker OD (2018) Carbon capture and storage, ed. p. Institute of Physics

46. Kulkarni AR, Sholl DS (2012) Analysis of Equilibrium-Based TSA Processes for Direct Capture of CO2 from Air. Ind Eng Chem Res 51(25):8631-8645

47. Su F et al (2010) Adsorption of $\mathrm{CO} 2$ on Amine-Functionalized Y-Type Zeolites. Energy Fuels 24(2):1441-1448

48. Rackley SA (2010) 9.3 Cryogenic Oxygen Production for Oxyfuel Combustion, in Carbon Capture and Storage, Elsevier

49. Shimekit B, Mukhtar H (2012) Natural Gas Purification Technologies - Major Advances for CO2 Separation and Future Directions

50. Berstad D, Anantharaman R, Nekså P (2013) Low-temperature $\mathrm{CO} 2$ capture technologies - Applications and potential. Int $\mathbf{J}$ Refrig 36(5):1403-1416

51. Lively RP, Koros WJ, Johnson JR (2012) Enhanced cryogenic $\mathrm{CO} 2$ capture using dynamically operated low-cost fiber beds. Chem Eng Sci 71:97-103

52. Surovtseva D (2010) CO2 separation by cryogenic and hydrate, in Curtin University. Department of Chemical Engineering, Clean Gas Technologies Australia

53. Kárászová M et al (2020) Post-combustion carbon capture by membrane separation. Rev Sep Purif Technol 238:116448

54. Vakharia V et al (2018) Scale-up of amine-containing thin-film composite membranes for $\mathrm{CO} 2$ capture from flue gas. J Membr Sci 555:379-387

55. Bernardo P, Drioli E, Golemme G (2009) Membrane Gas Separation: A Review/State of the Art. Ind Eng Chem Res 48(10):4638-4663

56. Yin H, Yip A (2017) A Review on the Production and Purification of Biomass-Derived Hydrogen Using Emerging Membrane Technologies. Catalysts 7:297

57. Norahim N et al (2018) Recent Membrane Developments for CO2 Separation and Capture. Chem Eng Technol 41(2):211-223

58. Lau WJ, Pérez de los Ríos A (2018) Membrane Separation. Chemical Engineering \& Technology, 41(2): p. 210-210.

59. Wong S, Bioletti R (2020) Carbon Dioxide Separation Technologies

60. Gielen D (2003) The energy policy consequences of future CO 2 capture and sequestration technologies in the 2nd annual conference on carbon sequestration. Alexandria, VA

61. Audus $\mathrm{H}$ (2000) Leading options for the capture of $\mathrm{CO} 2$ at power stations. Presented at the 5th International Conference on Greenhouse Gas Control Technologies, Cairns, Australia

62. Troy S, Schreiber A, Zapp P (2016) Life cycle assessment of membrane-based carbon capture and storage. Focusing on
Technology Research, Innovation, Demonstration, Insights and Policy Issues for Sustainable Technologies 18(6):1641-1654

63. Yang W, Cicek N, Ilg J (2006) State-of-the-art of membrane bioreactors: Worldwide research and commercial applications in North America. J Membr Sci 270(1):201-211

64. Lu GQ et al (2007) Inorganic membranes for hydrogen production and purification: A critical review and perspective. J Colloid Interface Sci 314(2):589-603

65. Iulianelli A, Drioli E (2020) Membrane engineering: Latest advancements in gas separation and pre-treatment processes, petrochemical industry and refinery, and future perspectives in emerging applications. Fuel Process Technol 206:106464

66. Hägg MB et al (2017) Pilot Demonstration-reporting on CO2 Capture from a Cement Plant Using Hollow Fiber Process. Energy Procedia 114:6150-6165

67. He X (2018) A review of material development in the field of carbon capture and the application of membrane-based processes in power plants and energy-intensive industries. Energy Sustain Soc $8(1): 34$

68. Merkel TC et al (2010) Power plant post-combustion carbon dioxide capture: An opportunity for membranes. J Membr Sci 359(1):126-139

69. Lonsdale HK (1989) Transport mechanisms in membrane separation processes : J.A. Bitter, Koninklijke/Shell-Laboratorium (Shell Research B.V.), P.O. Box 3003, 1003 AA Amsterdam, The Netherlands, 45 pages+viii appendices (no price). p. 191-192

70. Wong KK, and Jawad ZA (2019) A review and future prospect of polymer blend mixed matrix membrane for $\mathrm{CO} 2$ separation. J Polym Res 26(12)

71. Vinoba $M$ et al (2017) Recent progress of fillers in mixed matrix membranes for CO2 separation: A review. Sep Purif Technol 188:431-450

72. Ladewig B, Al-Shaeli MNZ (2017) Fundamentals of Membrane Processes. In: Ladewig B, Al-Shaeli MNZ (eds) Fundamentals of Membrane Bioreactors: Materials, Systems and Membrane Fouling. Springer Singapore, Singapore, p 13-37

73. Nunes SP, Peinemann KV (2006) Gas Separation with Membranes. Membr Technol p 53-90

74. Pandey P, Chauhan RS (2001) Membranes for gas separation. Prog Polym Sci 26(6):853-893

75. Sridhar S, Bee S, and Bhargava S (2014) Membrane-based Gas Separation: Principle, Applications and Future Potential. Chem Eng Dig

76. Pengilley C (2016) Membranes for gas separation. ProQuest Dissertations Publishing

77. Farsi A (2015) Mass transport in inorganic meso- and microporous membranes

78. Kobayashi S, and Müllen K (2015) Encyclopedia of Polymeric Nanomaterials / edited by Shiro Kobayashi, Klaus Müllen. Berlin, Heidelberg : Springer Berlin Heidelberg : Imprint: Springer

79. Galluci F, Basile A, Ibney Hai F (2011) Introduction - A Review of Membrane Reactors in Membranes for Membrane Reactors $p$ $1-61$

80. Wilcox J (2012) Technology M, in Carbon Capture. Springer. New York, NY p 177-218

81. Nagy E (2019) Chapter 3 - Mass Transport Through a Membrane Layer, in Basic Equations of Mass Transport Through a Membrane Layer (Second Edition), E. Nagy, Editor, Elsevier. p. 21-68

82. Ismail AF, Khulbe KC, Matsuura T. (2015) Gas Separation Membranes : Polymeric and Inorganic / by Ahmad Fauzi Ismail, Kailash Chandra Khulbe, Takeshi Matsuura, ed. K.a. Chandra Khulbe, T.a. Matsuura, and SpringerLink. Cham : Springer International Publishing : Imprint: Springer

83. Coronas J, Santamaría J (1999) Separations Using Zeolite Membranes. Sep Purif Methods 28(2):127-177 
84. Nagy E (2011) Basic Equations of the Mass Transport through a Membrane Layer

85. Abdelrasoul A et al (2015) Mass Transfer Mechanisms and Transport Resistances in Membrane Separation Process, p. 15-40.

86. Elfiana E et al (2019) Characterization Study of Inorganic Hybrid Membrane of Mixed Activated Zeolite and Clay with PVA Adhesives using Sintering Method for colourless Peat Water. IOP Conf Ser Mater Sci Eng 536:012036

87. Koros WJ, Mahajan R (2001) Pushing the limits on possibilities for large scale gas separation: which strategies? J Membr Sci 181(1):141

88. Paul DR, Kemp DR (1973) The diffusion time lag in polymer membranes containing adsorptive fillers. J Polym Sci: Polym Symp 41(1):79-93

89. Chung TS et al (2007) Mixed matrix membranes (MMMs) comprising organic polymers with dispersed inorganic fillers for gas separation. Prog Polym Sci 32(4):483-507

90. Bastani D, Esmaeili N, Asadollahi M (2013) Polymeric mixed matrix membranes containing zeolites as a filler for gas separation applications: A review. J Ind Eng Chem 19(2):375-393

91. Kulprathipanja S, Kulkarni S, Funk E (2020) Preparation of gas selective membranes

92. Buonomenna MG, Yave W, Golemme G (2012) Some approaches for high performance polymer based membranes for gas separation: block copolymers, carbon molecular sieves and mixed matrix membranes. RSC Adv 2(29):10745-10773

93. Mosleh S et al (2016) Synthesis and characterization of rubbery/ glassy blend membranes for $\mathrm{CO} 2 / \mathrm{CH} 4$ gas separation. J Polym Res 23(6): 120

94. Shekhawat D, Luebke D, Pennline H (2003) A Review of Carbon Dioxide Selective Membranes: A Topical Report

95. Farnam M, Mukhtar H, Shariff A (2014) A Review on Glassy Polymeric Membranes for Gas Separation. Appl Mech Mater 625:701-703

96. Swain $\mathrm{S}$ et al (2017) Carbon nanotubes as potential candidate for separation of $\mathrm{H} 2 / \mathrm{CO} 2$ gas pairs. Int J Hydrogen Energy 42

97. Alqaheem Y et al (2017) Polymeric Gas-Separation Membranes for Petroleum Refining. Int J Polym Sci 2017:1-19

98. George $\mathrm{G}$ et al (2016) Polymer membranes for acid gas removal from natural gas. Sep Purif Technol 158:333-356

99. Zhang Y et al (2013) Current status and development of membranes for $\mathrm{CO} 2 / \mathrm{CH} 4$ separation: A review. Int J Greenhouse Gas Control 12:84-107

100. Robeson LM (1991) Correlation of separation factor versus permeability for polymeric membranes. J Membr Sci 62(2):165-185

101. Freeman BD (1999) Basis of Permeability/Selectivity Tradeoff Relations in Polymeric Gas Separation Membranes. Macromolecules 32(2):375-380

102. Robeson LM (2008) The upper bound revisited. J Membr Sci 320(1):390-400

103. Crawford RJ, Throne JL (2002) 2 - ROTATIONAL MOLDING POLYMERS. In: Crawford RJ, Throne JL (eds) Rotational Molding Technology. William Andrew Publishing, Norwich, NY p 19-68

104. Ahmad AL et al (2015) Prediction of plasticization pressure of polymeric membranes for $\mathrm{CO} 2$ removal from natural gas. $\mathrm{J}$ Membr Sci 480:39-46

105. Houde AY et al (1996) Permeability of dense (homogeneous) cellulose acetate membranes to methane, carbon dioxide, and their mixtures at elevated pressures. J Appl Polym Sci 62(13):2181-2192

106. Mannan HA et al (2013) Recent Applications of Polymer Blends in Gas Separation Membranes. Chem Eng Technol 36(11):1838-1846

107. Guo S et al (2019) Controlling the pore size in conjugated polymer films via crystallization-driven phase separation. Soft Matter 15(14):2981-2989
108. Abdelgadir AKA et al (2020) The Influence of Embedding Different Loadings of MWCNTs on the Structure and Permeation of CAB Blended Membrane. J Phys Sci 31(1):15-36

109. Coveney S (2015) Fundamentals of Phase Separation in Polymer Blend Thin Films, Cham: Springer International Publishing. 1-6

110. Soleimany A, Hosseini SS, Gallucci F (2017) Recent progress in developments of membrane materials and modification techniques for high performance helium separation and recovery: A review. Chem Eng Process 122:296-318

111. Lillepärg J, Georgopanos P, Shishatskiy S (2014) Stability of blended polymeric materials for $\mathrm{CO} 2$ separation. J Membr Sci 467:269-278

112. Jujie L, He X, Si Z (2017) Polysulfone membranes containing ethylene glycol monomers: synthesis, characterization, and $\mathrm{CO}$ 2 /CH 4 separation. J Polym Res 24(1):1-14

113. Yang ZZ, Song QW, He LN (2012) Capture and Utilization of Carbon Dioxide with Polyethylene Glycol. SpringerLink. Berlin, Heidelberg Imprint: Springer

114. Kuehne DL, Friedlander SK (1980) Selective Transport of Sulfur Dioxide through Polymer Membranes. 1. Polyacrylate and Cellulose Triacetate Single-Layer Membranes. Ind Eng Chem Process Des Dev 19(4) p 609-616

115. Wong KK, Jawad ZA, Chin BLF (2021) A polyethylene glycol (PEG) - polyethersulfone (PES)/multi-walled carbon nanotubes (MWCNTs) polymer blend mixed matrix membrane for $\mathrm{CO} 2 / \mathrm{N} 2$ separation. J Polym Res 28(1):6

116. Car A et al (2008) Pebax $® /$ polyethylene glycol blend thin film composite membranes for $\mathrm{CO} 2$ separation: Performance with mixed gases. Sep Purif Technol 62(1):110-117

117. Sidik A, Othaman R, Anuar F (2018) The Effect of Molecular Weight on the Surface and Permeation of Poly(L-lactic acid)Poly(ethylene glycol) Membrane with Activated Carbon Filler. Sains Malaysiana 47:1181-1187

118. Zuo DY et al (2011) The influence of PEG molecular weight on morphologies and properties of PVDF asymmetric membranes. Chinese J Polym Sci 26

119. Boutilier MSH, Hadjiconstantinou NG, Karnik R (2017) Knudsen effusion through polymer-coated three-layer porous graphene membranes. Nanotechnology 28(18):184003

120. Lin H, Freeman BD (2005) Materials selection guidelines for membranes that remove $\mathrm{CO} 2$ from gas mixtures. J Mol Struct 739(1):57-74

121. Karimi S, Firouzfar E, Khoshchehreh MR (2019) Assessment of gas separation properties and $\mathrm{CO} 2$ plasticization of polysulfone/ polyethylene glycol membranes. J Petrol Sci Eng 173:13-19

122. Hamrahi Z, Kargari A (2017) Modification of polycarbonate membrane by polyethylene glycol for $\mathrm{CO} 2 / \mathrm{CH} 4$ separation. Sep Sci Technol 52(3):544-556

123. Akbarian I et al (2018) Gas-separation behavior of poly(ether sulfone)-poly(ethylene glycol) blend membranes. J Appl Polym Sci 135(44): 46845

124. Isfahani AP et al (2017) Enhancement of CO2 capture by polyethylene glycol-based polyurethane membranes. J Membr Sci 542:143-149

125. Hu $\mathrm{T}$ et al (2013) Improved CO2 separation performance with additives of PEG and PEG-PDMS copolymer in poly(2,6-dimethyl-1,4-phenylene oxide)membranes. J Membr Sci 432:13-24

126. Li J et al (1998) Effect of polyethyleneglycol (PEG) on gas permeabilities and permselectivities in its cellulose acetate (CA) blend membranes. J Membr Sci 138(2):143-152

127. Naderi A et al (2018) Effects of chemical structure on gas transport properties of polyethersulfone polymers. Polymer 135:76-84

128. Mannan H, Mukhtar H, Murugesan T (2014) Polyethersulfone (PES) Membranes for $\mathrm{CO} 2 / \mathrm{CH} 4$ Separation: Effect of Polymer 
Blending. Applied Mechanics and Materials, 625(Process Adv Mater Engg) p 172-175

129. Mustafa J, Farhan M (2016) CO2 Separation from Flue Gases Using Different Types of Membranes. J Membr Sci Technol 6

130. Kamal SNM et al (2014) Effects of THF as cosolvent in the preparation of polydimethylsiloxane/polyethersulfone membrane for gas separation. Polym Eng Sci 54(9):2177-2186

131. Kapantaidakis $\mathrm{G}$ et al (2003) CO2 plasticization of polyethersulfone/ polyimide gas-separation membranes. American Institute of Chemical Engineers. AIChE J 49(7) p 1702

132. Mannan HA et al (2016) Polysulfone/poly(ether sulfone) blended membranes for CO2 separation. J Appl Polym Sci 133(5)

133. Hasanajili S, Latifzadeh M, Bahmani M (2017) Permeation properties of $\mathrm{CO} 2$ and $\mathrm{CH} 4$ in asymmetric polyethersulfone/ polyesterurethane and polyethersulfone/polyetherurethane blend membranes. Chin J Chem Eng 25(12):1750-1759

134. Li FY et al (2011) Development and positron annihilation spectroscopy (PAS) characterization of polyamide imide (PAI)-polyethersulfone (PES) based defect-free dual-layer hollow fiber membranes with an ultrathin dense-selective layer for gas separation. J Membr Sci 378(1):541-550

135. Sharif A et al (2012) Improvement of CO $2 / \mathrm{CH} 4$ separation characteristics of polyethersulfone by modifying with polydimethylsiloxane and nano-silica. J Polym Res 19(7):1-8

136. Yong WF et al (2018) New polyethersulfone (PESU) hollow fiber membranes for CO2 capture. J Membr Sci 552:305-314

137. Chung, TS and Khean Teoh S (1999) The ageing phenomenon of polyethersulphone hollow fibre membranes for gas separation and their characteristics. J Membr Sci 152(2) p 175-188

138. Chung TS et al (1998) Effect of shear stress within the spinneret on hollow fiber membrane morphology and separation performance. Ind Eng Chem Res 37(10):3930-3938

139. Zhao $C$ et al (2013) Modification of polyethersulfone membranes - A review of methods. Prog Mater Sci 58(1):76-150

140. Usula M et al (2014) The structural organization of N-methyl2-pyrrolidone + water mixtures: A densitometry, $\mathrm{x}$-ray diffraction, and molecular dynamics study. J Chem Phys 140(12):124503

141. Basma NS et al (2018) Local Structure and Polar Order in Liquid N-Methyl-2-pyrrolidone (NMP). J Phys Chem B 122(38):8963-8971

142. Mubashir M et al (2018) Enhanced Gases Separation of Cellulose Acetate Membrane Using N-Methyl-1-2 Pyrrolidone as Fabrication Solvent. International Journal of Automotive and Mechanical Engineering 15(1):4978-4986

143. Askari M, Chung TS (2013) Natural gas purification and olefin/ paraffin separation using thermal cross-linkable co-polyimide/ ZIF-8 mixed matrix membranes. J Membr Sci 444:173-183

144. Jusoh $\mathrm{N}$ et al (2016) Facile fabrication of mixed matrix membranes containing 6FDA-durene polyimide and ZIF-8 nanofillers for CO2 capture. J Ind Eng Chem 44:164-173

145. Juber FAH et al Development of Novel Blend Poly (Ethylene Glycol) / Poly(Ethersulfone) Polymeric Membrane Using N-Methyl-2-Pyrollidone And Dimethylformamide Solvents for Facilitating CO2/N2 Gas Separation. Materials Today: Proceedings, in press

146. Isanejad M, Azizi N, Mohammadi T (2017) Pebax membrane for $\mathrm{CO} 2 / \mathrm{CH} 4$ separation: Effects of various solvents on morphology and performance. J Appl Polym Sci 134(9)

147. Ahmad A, Olatunji S, Jawad Z (2017) Thickness Effect on the Morphology and Permeability of CO sub(2)/N sub(2) Gases in Asymmetric Polyetherimide Membrane. J Phys Sci 28:201-201

148. Kamble AR, Patel CM, Murthy ZVP (2020) Different 2D materials based polyetherimide mixed matrix membranes for $\mathrm{CO} 2 /$ N2 separation. J Ind Eng Chem 81:451-463

149. Wang D, Li K, Teo WK (1996) Polyethersulfone hollow fiber gas separation membranes prepared from NMP/alcohol solvent systems. J Membr Sci 115(1):85-108
150. Tavasoli E et al (2018) Gas Separation Polysulfone Membranes Modified by Cadmium-based Nanoparticles. Fiber Polym 19(10):2049-2055

151. Moghadassi AR et al (2014) Fabrication and modification of cellulose acetate based mixed matrix membrane: Gas separation and physical properties. J Ind Eng Chem 20(3):1050-1060

152. Ahmad MS et al (2018) Effect of solvents on the morphology and performance of Polyethersulfone (PES) polymeric membranes material for $\mathrm{CO} 2 / \mathrm{CH} 4$ separation

153. International Agency for Research on Cancer Content (1989) Some organic solvents, resin monomers, and related compounds, pigments, and occupational exposures in paint manufacture and painting. IARC Geneva Switzerland Distributed for the International Agency for Research on Cancer by th.

154. Jödecke MÁ, Pérez-Salado Kamps, Maurer G (2012) An Experimental Investigation of the Solubility of $\mathrm{CO} 2$ in (N,N-Dimethylmethanamide + Water). J Chem Eng Data 57(4):1249-1266

155. Karamouz F, Maghsoudi H, Yegani R (2016) Synthesis and characterization of high permeable PEBA membranes for $\mathrm{CO} 2 / \mathrm{CH} 4$ separation. J Nat Gas Sci Eng 35:980-985

156. Kizildag N et al. (2015) Polyacrylonitrile/polyaniline composite nano/microfiber webs produced by different dopants and solvents. $\mathrm{J}$ Ind Text 46

157. Shao L et al (2004) Casting solvent effects on morphologies, gas transport properties of a novel 6FDA/PMDA-TMMDA copolyimide membrane and its derived carbon membranes. J Membr Sci 244(1):77-87

158. Shangguan Y (2011) Intrinsic Properties of Poly (EtherB-Amide)(Pebax $\left.{ }^{\circledR} 1074\right)$ for Gas Permeation and Pervaporation, University of Waterloo

159. Alqaheem Y, Alomair AA (2020) Minimizing Solvent Toxicity in Preparation of Polymeric Membranes for Gas Separation. ACS Omega 5(12):6330-6335

160. Ma XH, and Yang SY (2018) Chapter 6 - Polyimide Gas Separation Membranes, in Advanced Polyimide Materials, SY Yang (ed) Elsevier. p 257-322

161. Amirilargani M, Sadrzadeh M, Mohammadi T (2010) Synthesis and characterization of polyethersulfone membranes. J Polym Res 17(3):363-377

162. Mulder M (2012) Basic principles of membrane technology. Springer Science \& Business Media

163. Drioli E, Giorno L (2009) Membrane operations: innovative separations and transformations. John Wiley \& Sons

164. Figoli A et al (2014) Towards non-toxic solvents for membrane preparation: a review. Green Chem 16(9):4034-4059

165. Khorsand-Ghayeni $M$ et al (2017) Fabrication of asymmetric and symmetric membranes based on PES/PEG/DMAc. Polym Bull 74(6):2081-2097

166. Zare S, Kargari A (2018) 4 - Membrane properties in membrane distillation, in Emerging Technologies for Sustainable Desalination Handbook, V.G. Gude, Editor, Butterworth-Heinemann. p. $107-156$

167. Xiao $\mathrm{T}$ et al (2015) Fabrication and characterization of novel asymmetric polyvinylidene fluoride (PVDF) membranes by the nonsolvent thermally induced phase separation (NTIPS) method for membrane distillation applications. J Membr Sci 489:160-174

168. Eykens L et al (2017) Membrane synthesis for membrane distillation: A review. Sep Purif Technol 182:36-51

169. Purkait MK et al (2018) Chapter 1 - Introduction to Membranes, in Interface Science and Technology. MK Purkait et al. (eds) Elsevier $\mathrm{p} 1-37$

170. Ismail AF, Khulbe KC, Matsuura T (2019) Chapter 2 - RO Membrane Preparation, in Reverse Osmosis. AF Ismail, KC Khulbe, T Matsuura (eds) Elsevier p 25-56 
171. Loeb S, Sourirajan S (1963) Sea Water Demineralization by Means of an Osmotic Membrane, in Saline Water ConversionII. Am Chem Soc. p 117-132

172. Zhang Z et al (2018) Chapter 50 - Zeolites Nanocomposite Membrane Applications in CO2 Capture, in Handbook of Nanomaterials for Industrial Applications. C Mustansar Hussain (ed) Elsevier p 916-921

173. Strathmann H, Kock K (1977) The formation mechanism of phase inversion membranes. Desalination 21(3):241-255

174. Nath K (2017) Membrane separation processes. PHI Learning Pvt. Ltd

175. Kesting RE (1985) Synthetic polymeric membranes: a structural perspectives

176. Hołda AK, Vankelecom IFJ(2015) Understanding and guiding the phase inversion process for synthesis of solvent resistant nanofiltration membranes. J Appl Polym Sci 132(27)

177. Xiao P et al (2015) A sacrificial-layer approach to fabricate polysulfone support for forward osmosis thin-film composite membranes with reduced internal concentration polarisation. J Membr Sci 481:106-114

178. Mansourpanah Y, Ostadchinigar A (2017) Preparation of chemically attached polyamide thin film membrane using different diamines: separation and computational investigation. J Polym Res 24(2):26

179. $\mathrm{Ng} \mathrm{S}$ et al (2020) Influence of Polymer Blending of Cellulose Acetate Butyrate for CO2/N2 Separation. J Phys Sci 31:69-84

180. Zhou $Z$ et al (2016) Effect of surface properties on antifouling performance of poly(vinyl chloride-co-poly(ethylene glycol) methyl ether methacrylate)/PVC blend membrane. J Membr Sci 514:537-546

181. Sadeghi M et al (2008) Gas permeation properties of polyvinylchloride/polyethyleneglycol blend membranes. J Appl Polym Sci 110(2):1093-1098

182. Hamzah S et al (2014) High performance of polysulfone ultrafiltration membrane: effect of polymer concentration. J Eng Appl Sci 9(12):2543-2560

183. Ismail $\mathrm{N}$ et al (2017) Effect of Polymer Concentration on the Morphology and Mechanical Properties of Asymmetric Polysulfone (PSf) Membrane. J Appl Membr Sci Technol 21

184. Kumar H, Siddaramaiah A (2005) study of sorption/desorption and diffusion of substituted aromatic probe molecules into semi interpenetrating polymer network of polyurethane/polymethyl methacrylate. Polymer 46(18):7140-7155

185. Chong DS et al (2020) The Influence of Blending Different Molecular Weights of Cellulose Acetate Butyrate for CO2/N2 Separation. J Phys Sci 31(2):91-112
186. Idris A et al (2002) Optimization of cellulose acetate hollow fiber reverse osmosis membrane production using Taguchi method. J Membr Sci 205(1):223-237

187. Jami' an WNR et al (2016) Effect of evaporation time on cellulose acetate membrane for gas separation. IOP Conf Ser Earth Environ Sci 36:012008

188. Fashandi H, Karimi M (2014) Evidence for the impression of phase behavior of nonsolvent/solvent/polymer ternary system on morphology of polyethersulfone electrospun nanofibers. Fiber Polym 15(7):1375-1386

189. Mansourizadeh A, Ismail AF (2010) Effect of additives on the structure and performance of polysulfone hollow fiber membranes for CO2 absorption. J Membr Sci 348(1):260-267

190. Azari S, Karimi M, Kish MH (2010) Structural Properties of the Poly(acrylonitrile) Membrane Prepared with Different Cast Thicknesses. Ind Eng Chem Res 49(5):2442-2448

191. Jawad ZA et al (2015) Influence of solvent exchange time on mixed matrix membrane separation performance for $\mathrm{CO} 2 / \mathrm{N} 2$ and a kinetic sorption study. J Membr Sci 476:590-601

192. Vogrin $\mathrm{N}$ et al (2002) The wet phase separation: the effect of cast solution thickness on the appearance of macrovoids in the membrane forming ternary cellulose acetate/acetone/water system. J Membr Sci 207(1):139-141

193. Sugu L, Jawad Z (2019) Formation of Low Acetyl Content Cellulose Acetate Membrane for CO2/N2 Separation. J Phys Sci 30(1):111-125

194. Cha WC, Jawad ZA (2020) The influence of cellulose acetate butyrate membrane structure on $\mathrm{CO} 2 / \mathrm{N} 2$ separation: effect of casting thickness and solvent exchange time. Chem Eng Commun 207(4):474-492

195. Mulder M (1992) Basic Principles of Membrane Technology, Kluwer Academic Publishers, Dordrecht, Boston, London, 1991, ISBN 0-7923-0978-2, 363 Seiten, Preis: DM 200,- . Berichte der Bunsengesellschaft für physikalische Chemie 96(5): p. 741-742

196. Rahman MM et al (2018) CO2 Selective PolyActive Membrane: Thermal Transitions and Gas Permeance as a Function of Thickness. ACS Appl Mater Interfaces 10(31):26733-26744

197. Farnam M, Mukhtar H, Shariff AM (2016) An investigation of blended polymeric membranes and their gas separation performance. RSC Adv 6(104):102671-102679

Publisher's Note Springer Nature remains neutral with regard to jurisdictional claims in published maps and institutional affiliations. 